\title{
Capital Tax Reforms With Policy Uncertainty
}

Working Paper 2021-01

Arpad Abraham, PAVEl BREndler AND Eva

CARCELES

March, 2021

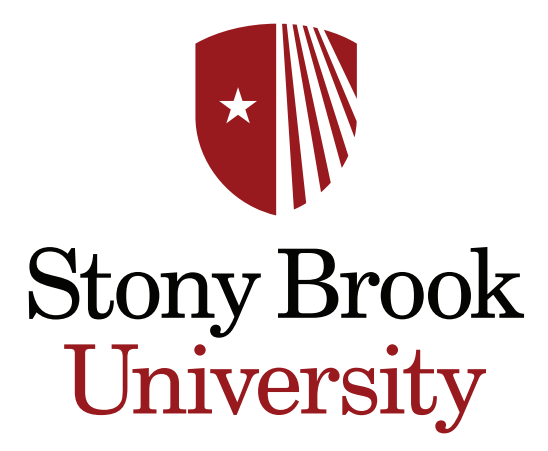




\title{
Capital Tax Reforms With Policy Uncertainty*
}

\author{
Arpad Abraham \\ University of Bristol
}

\author{
Pavel Brendler \\ University of Bonn
}

March 13, 2021

\author{
Eva Carceles \\ Stony Brook University
}

\begin{abstract}
One important feature of capital tax reforms is uncertainty regarding their duration. We use the Bush Tax cuts as the leading example to illustrate how uncertainty about reform duration may affect the economy's path and erode political support for the reform. We model policy uncertainty by assuming that the reform may be either repealed or made permanent with some probability at a predetermined date. We show that policy uncertainty is a critical ingredient that can explain why the Bush tax cuts had no economically significant effect on investment, as confirmed empirically by Yagan (2015). While the permanent reform leads to positive aggregate welfare gains on impact, policy uncertainty may reverse this result. These observations hold both in a model with a representative firm and heterogeneous firms, but adding firm heterogeneity generates an interesting implication. In contrast to the permanent reform, policy uncertainty increases the TPF since it dampens investment by mature, less productive firms.
\end{abstract}

Key words: Policy uncertainty, Capital gains tax, Dividend tax policies, Investment and financial policies, Intertemporal tax arbitrage.

JEL codes: E20, E44, H24, H31.

${ }^{*}$ We are thankful for useful comments and suggestions to Christian Bayer, Jeremy Boccanfuso, Luigi Bocola, Gianluca Clementi, Pawel Doligalski, Joachim Jungherr, Gianluca Violante as well as the seminar participants at several seminars and conferences. All errors are ours. 


\section{Introduction}

Tax reforms, in particular capital tax reforms, are constantly on the policy agenda in most developed countries. One critical feature of these reforms is the uncertainty surrounding them. It is usually not clear whether they will be permanent or whether subsequent governments will overturn them. The expected duration of the reform is important because it can potentially affect agents' economic decisions, welfare, and political support. For example, households who would otherwise support reform with a certain duration might oppose the same reform if there is sufficiently large uncertainty regarding whether it will become permanent. This paper illustrates how uncertainty surrounding the duration of capital tax reforms can potentially affect the economy's path and erode political support.

Uncertainty surrounding policy proposals is particularly interesting in the US for two reasons. First, even reforms that have an "expiration date" can be extended by the next administration. For example, President George W. Bush's Jobs and Growth Tax Relief Reconciliation Act (JGTRRA) of 2003 was set to expire after 2010. Despite this, it was extended during the presidency of Barack Obama and eventually became permanent for most income earners in 2012. At the same time, President Trump's Tax and Growth Job Act of 2017, which reduced corporate profit taxes permanently and simplified the personal income tax brackets, has a provision stipulating that the personal income tax changes will expire in 2026. However, it is not obvious whether subsequent administrations will extend it. Second, reforms that are originally designed to be "permanent" also face the risk of being overturned by subsequent governments, especially if the administration changes from a liberal to a conservative government or vice versa. Consider, for example, the recent attempts by President Donald Trump to abolish "Obamacare".

In this paper, we use a standard macroeconomic model with heterogeneous firms to analyze the conditions under which policy uncertainty makes a difference for aggregate economic outcomes and welfare. A vast majority of the related studies assume that tax reforms are permanent. However, policy uncertainty will matter in a qualitative sense if it is sufficiently strong to affect the agents' behavior. A setting with shareholder and corporate taxation is a great candidate to illustrate this point. The future stochasticity in taxes created by policy uncertainty has important consequences for investment and pay-out policies if firms and shareholders would like to take advantage of tax arbitrage opportunities. Moreover, the effect of these arbitrage opportunities will be enhanced in the presence of frictions such as capital adjustment costs and consumption smoothing motives due to risk aversion on the shareholder/consumer side.

Our main focus is the JGTRRA, which we use as a benchmark case for two reasons. 
First, there was substantial uncertainty in public about its permanency. Second, the literature (see e.g. Yagan (2015)) has not found any economically significant causal effects on investment from reducing dividend taxes. This finding is in sharp contrast with policymakers' expectations and the predictions of existing economic models that the reform would generate an investment boom. In particular, traditional models of corporate finance ${ }^{1}$ sug- $^{-}$ gest that lowering dividend taxes will reduce the firms' cost of capital and hence stimulate investment, which tends to respond strongly to changes in the cost of capital ${ }^{2}$. Indeed, this type of argument has been used to motivate the tax reform proposal in the past and more recently.

Yagan (2015), however, provides three alternative reasons that could help explain why we have not seen an increase in investment after the JGTRRA reform. First, as opposed to the traditional view of corporate finance, the "new view" assumes that firms do not use new equity to finance investment but rather retained earnings (see e.g. King (1977), Auerbach (1979), Bradford (1981)). In this case, dividend taxes, as long as they are constant, do not affect investment. Second, there was considerable uncertainty about the duration of the JGTRAA that could have potentially diminished its effect on investment. Third, a significant part of shareholder taxation occurs through capital gains taxation, another key aspect of the JGTRAA reform that can interact with the effectiveness of the dividend tax reform. In this paper, we consider these three aspects by building a model with: (i) dynamic firms that use retained earnings to finance investment, and (ii) shareholders who pay both dividend and capital gains taxes while the firm pays corporate taxes. Our main experiment proxies the JGTRAA because we reduce both dividend and capital gains taxes and account for the uncertainty regarding reform's permanency, which we refer to as "policy uncertainty".

We model policy uncertainty as follows. We assume that the government makes an unexpected announcement that it will change the policy in a given period. However, the duration of the reform is uncertain. With some probability, the policy change will become permanent at a pre-determined period in the future. However, the reform might also be repealed (irreversibly) at that period. Ex-ante, all agents know the probability distribution. This modeling of policy uncertainty is motivated by "the expiry dates" or "sunset clauses" of reforms that are typical in US legislation.

Using a calibrated general equilibrium model with policy uncertainty, we show that our model can explain the muted response of investment following the JGTRRA reform. In our environment, a permanent reduction of only dividend taxes would lead to no response of investment (in line with the "new view"). However, under policy uncertainty, the reduction

\footnotetext{
${ }^{1}$ See, for example, Harberger (1962), Feldstein (1970), and Poterba \& Summers (1983).

${ }^{2}$ See, for example, Hall \& Jorgenson (1969), and Caballero et al. (1995).
} 
in dividend taxes leads to a reduction in investment until uncertainty about the reform's permanency is resolved. The key reason is that, before the predetermined date when the reform is either repealed or made permanent, dividend tax rates will increase in expectation as long as there is a positive probability that the reform will be reversed. This implies that shareholders will want to increase dividends and reduce investment the period before uncertainty is resolved to take advantage of the lower current dividend taxes. With convex capital adjustment costs and risk aversion on the shareholders' side, this effect is spread out to the initial periods, implying that investment will decline on impact as well. In sum, a dividend tax cut alone does not produce a muted response for investment in the presence of policy uncertainty. In order to generate that, we need to consider the capital gains tax cuts as well.

Looking at the effects of a reduction in capital gains taxes, we first notice that lowering capital gains taxes permanently leads to an increase in investment and the firm's value through its effect on the cost of capital. This effect not only survives under policy uncertainty but it is amplified for two reasons. First, policy uncertainty, like any risk, will imply some additional precautionary savings motives for the shareholders. Second, since we model capital gains taxation as accrual-based (similarly to the vast majority of the literature), policy uncertainty introduces another tax arbitrage opportunity. Capital gains taxes are low during firm growth, but they will be high during a period in which the firm value is declining if the reform is repealed, implying that the shareholders will be receiving high rebates. Given this, a pure capital gain tax reform will lead to a short-run increase in investment under policy uncertainty, which is even higher than under a permanent reform.

When we reduce both shareholder taxes, the model delivers a muted response of investment under policy uncertainty because the opposing effects of the dividend and capital gain tax changes approximately offset each other. This muted response of investment cannot be obtained under a permanent reform, which leads to a considerable increase in investment that we did not observe in the data.

The mechanisms described above hold in a model with a representative firm and a representative household. However, these capital tax reforms affect firms at different stages of their lifecycle differently in a setting with firm heterogeneity. For example, firms that operate at a smaller scale than their efficient level are growing and not paying dividends. In contrast, firms that have reached their mature level of operations do pay dividends but do not grow in value. For this reason, we also study this policy reform in a version of the model where firms face idiosyncratic productivity shocks and go through different lifecycle stages.

While the same aggregate results hold in this version of the model, adding firm heterogeneity generates an additional interesting implication. If the joint tax reform is permanent, 
the aggregate TFP declines. In this case, mature firms, who behave largely like a representative firm, will tend to increase their investment and become bigger, while growing firms will be largely unaffected. Hence, the tax reform reallocates resources towards the mature, less productive firms. Under policy uncertainty, however, mature (dividend-paying) firms reduce their investment in the short-run to take advantage of the lower dividend tax. Hence, resources are reallocated towards growing firms, generating an increase in the aggregate TFP. Note also that the heterogeneous firm environment provides more testable hypotheses on the differential effects of the tax reforms on firms at different stages of their lifecycle, an aspect that we plan to study in the future. Besides, the heterogeneous firm case also provides us with an interesting normative implication. This tax reform would deliver positive welfare gains if it were permanent. We show that policy uncertainty is not only important for the effectiveness of the reform, but it could also change the reform's desirability.

Finally, we study the effects of a corporate tax cut that corresponds to the one implemented by the Trump administration. The corporate tax cut boosts investment regardless of policy uncertainty since it increases the return to investment for all firms. While this reform is similar to a capital gains tax cut, the two reforms feature important differences under policy uncertainty. When capital gains taxes decline, policy uncertainty amplifies the investment response compared to the permanent reform. On the contrary, the investment response is mitigated following a reduction in corporate taxes. The reason is that capital gains tax cuts, like dividend taxes, provide tax arbitrage opportunities that induce firms to overinvest, an effect that is absent in the case of corporate tax cuts. Simultaneously, the corporate tax cut amplifies TFP compared to the capital gains tax cut because it leads growing and more productive firms to invest more and mature firms to invest less.

Even though policy uncertainty can be potentially very important, there has been little research studying the economic and welfare effects of policy uncertainty in quantitative macroeconomic models with heterogeneous households. The previous literature on income tax reforms, such as Domeij \& Heathcote (2004), Conesa \& Krueger (2006), Conesa et al. (2009) and Abraham \& Carceles-Poveda (2006), has studied the aggregate and distributional effects of either ex-ante and ex-post permanent income tax reforms. Anagnostopoulos et al. (2012) and Carceles-Poveda \& Coen-Pirani (2009) study the effects of corporate and dividend tax reforms on capital accumulation. Again, the reforms in these papers are deterministic. A few notable exceptions in the literature include Caliendo et al. (2015) and Kitao (2018), which address the uncertainty surrounding the sustainability of Social Security. Calvo \& Drazen (1997) focus on the uncertain duration of trade liberalization policies.

To the best of our knowledge, this is the first paper studying quantitatively the effects of policy uncertainty when implementing shareholder tax reforms in general equilibrium. 
Korinek \& Stiglitz (2009) studies dividend tax reforms in a partial equilibrium with and without policy uncertainty. Compared to them, we have a full quantitative general equilibrium model where taxes are levied both on dividends and on capital gains. The Bush tax cuts were also analysed in a quantitative general equilibrium model in Gourio \& Miao (2011) and Anagnostopoulos et al. (2018). However, they study these tax reforms in the absence of policy uncertainty.

\section{Model Environment}

\section{$2.1 \quad$ Overview}

In this section, we present an infinite horizon economy that features firm heterogeneity. In the general model, the economy is populated by a government, a continuum (measure 1) of firms and a continuum (measure 1) of infinitely lived households. For our quantitative experiments, we will study two cases of the general model, which include a version with heterogeneity at the firm level, and a version with no heterogeneity at all, which we label rep model.

We are going to study policy reforms that are unanticipated and announced at time $t=1$, becoming effective immediately, i.e., in the period of announcement. These reforms will stay in place with certainty until period $T^{\star}>1$. At that period, with probability $p$, they are made permanent and with probability $1-p$ they are withdrawn and the policy parameters are changed back to the original ones. Whenever we have $0<p<1$, our economy features policy uncertainty. Note that in the case of $p=0$, we have a pure temporary reform of duration $T^{\star}$ and whenever $p=1$ we have a permanent reform.

This approach of modeling policy uncertainty provides us with a tractable formulation. The economy follows a deterministic path until period $T^{\star}-1$. Nevertheless, policy uncertainty (i.e., the particular value of $p$ ) affects economic decisions during this stage even though no new aggregate information is revealed during this initial stage. The economy follows a deterministic path also after period $T^{\star}$ and it converges to a new steady-state if the reform is made permanent or it converges back to the original steady-state otherwise. This implies that agents (firms and households) face stochasticity in a recursive (period-by-period) sense only in period $T^{\star}-1$.

This way of modeling uncertainty is motivated by the uncertainty that surrounded the reforms we study in the real world. As for the Bush tax cuts, the initial reform was implemented in 2003, but there was always uncertainty about whether it would be revoked before 2012. This uncertainty got finally resolved in 2012, which would represent $T^{\star}$ in our 
model. Whereas the reform was made permanent for most American earners in 2012, there was always a probability that it would be revoked until then. Similarly, the Trump tax cuts were implemented in 2017 but the reform establishes that the personal income tax changes will expire in 2026. Moreover, Trump's opponent already has stated that he would repeal parts of the tax cuts is he is elected.

\subsection{Households}

The representative household is endowed with one unit of time which he supplies inelastically to the firm sector. Households are indifferent about working for any firm. Hence, the allocation of labor across firms is determined by the labor demand of individual firms. Household's preferences over consumption $c$ are assumed to be of the following form:

$$
u(c)=\frac{c^{1-\sigma}}{1-\sigma},
$$

where $\sigma$ is the level of risk aversion.

Households pay a proportional tax $\tau_{i, t}$ on their pre-tax labor earnings, which are given by $w_{t} n_{t}$, where $w_{t}$ is a wage rate and $n_{t}$ is the labor supply. Households can trade in shares of each firm. We denote the share of firm $j$ that is held by the representative household by $\theta_{t}^{j}$ and the ex dividend price of this share is denoted by $P_{t}^{j}$. Holding firm shares provides income to the household in the form of dividends, $d_{t}^{j}$, as well as capital gains resulting from changes in the market value of these shares. Households pay proportional taxes $\tau_{d, t}$ and $\tau_{g, t}$ on their dividend income and capital gains income, respectively. Given perfect competition, prices and dividends are taken as given by the households.

Households can use their after-tax income from all sources to purchase consumption goods, buy one period bond holdings $b_{t}$ that pay an after-tax interest rate of $\left(1-\tau_{i, t}\right) r_{t}$, or buy new shares $\theta_{t+1}^{j}$ of every firm at the market price $P_{t}^{j}$. After-tax income includes labor income and the income from holding the firm shares. Shares in firm $j$ entitle the household to a net dividend income of $\left(1-\tau_{d, t}\right) d_{t}^{j} \theta_{t}^{j}$. The shareholder can sell her existing shares at $P_{t}^{j}$ and the increase in the value of this existing equity $\left(P_{t}^{j}-P_{t-1}^{j}\right) \theta_{t}^{j}$ represents accrued capital 
gains. $^{3}$ The household's budget constraint can be expressed as:

$$
\begin{aligned}
c_{t} & =\left(1-\tau_{i, t}\right) w_{t} n_{t}+\int_{j}\left[\left(1-\tau_{d, t}\right) d_{t}^{j} \theta_{t}^{j}+P_{t}^{j} \theta_{t}^{j}-\tau_{g, t}\left(P_{t}^{j}-P_{t-1}^{j}\right) \theta_{t}^{j}-P_{t}^{j} \theta_{t+1}^{j}\right] d j \\
& +\left(1+r_{t}\left(1-\tau_{i, t}\right)\right) b_{t}-b_{t+1}+Z_{t},
\end{aligned}
$$

where $Z_{t}$ is a lump sum transfer from the government.

In each period, households choose how much to consume and how many shares to buy taking as given the sequence ${ }^{4}$ of wages, share prices and dividends, $\left\{w_{t},\left\{P_{t}^{j}, d_{t}^{j}\right\}_{j \in[0,1]}\right\}_{t=1}^{\infty}$, the sequence of taxes, $\left\{\tau_{l, t}, \tau_{d, t}, \tau_{g, t}\right\}_{t=1}^{\infty}$ and the initial asset holdings $b_{1}$ and $\theta_{1}^{j}$ for all $j$. The optimality conditions of this problem (for all $t \geq 1$ and $j$ ) are given by:

$$
\begin{gathered}
P_{t}^{j}=E_{t}\left[m_{t, t+1}\left(\left(1-\tau_{d, t+1}\right) d_{t+1}^{j}+P_{t+1}^{j}-\tau_{g, t+1}\left(P_{t+1}^{j}-P_{t}^{j}\right)\right)\right], \\
1=E_{t}\left[m_{t, t+1}\left(1-\tau_{i, t+1}\right) r_{t+1}\right]
\end{gathered}
$$

where $m_{t, t+1}=\frac{\beta u^{\prime}\left(c_{t+1}\right)}{u^{\prime}\left(c_{t}\right)}$ is the (possibly stochastic) marginal rate of substitution for the representative household. ${ }^{5}$ Note that the expectation reflects the fact that there is aggregate risk generated by policy uncertainty.

\section{$2.3 \quad$ Firms}

Firms use capital $k$ and labor $l$ to produce consumption goods $y$ using a Cobb-Douglas production function with decreasing returns to scale:

$$
y=z f(k, l)=z k^{\alpha_{k}} l^{\alpha_{l}}
$$

where $0<\alpha_{k}, \alpha_{l}<1$ and $\alpha_{k}+\alpha_{l} \leq 1$. Production is subject to an idiosyncratic productivity shock $z$ which is i.i.d. across firms and follows a Markov process with transition matrix $\pi_{z}\left(z^{\prime} \mid z\right)$ and $N_{z}$ possible values. We now consider the problem of a particular firm $j$.

Each period $t$, given the available capital and the current productivity realization, firm $j$ chooses labor demand optimally. The choice of labor demand is a static problem and it

\footnotetext{
${ }^{3}$ We make the simplifying assumption that capital gains taxes are paid on an accrual basis and that capital losses are subsidized at the same rate. This is the standard approach in the literature with the notable exceptions of Gavin et al. (2007) and Dammon et al. (2001).

${ }^{4}$ This notation here and below is implicit about the fact that from period $T^{\star}$ on, there are two possible values of all these variables depending on whether the reform is withdrawn or not.

${ }^{5}$ In all periods but $T^{*}-1, m_{t, t+1}$ is a constant, but in period $T^{*}-1$ it is stochastic.
} 
defines the operating profit of the firm as follows:

$$
\pi\left(k_{t}^{j}, z_{t}^{j} ; w_{t}\right) \equiv \max _{l_{t}^{j}}\left\{z_{t}^{j} f\left(k_{t}^{j}, l_{j, t}\right)-w_{t} l_{t}^{j}\right\}
$$

where $w_{t}$ is the economy-wide wage rate. The firm's labor demand is determined by the following optimality condition:

$$
w_{t}=\alpha_{l} z_{t}^{j}\left(k_{t}^{j}\right)^{\alpha_{k}}\left(l_{t}^{j}\right)^{\alpha_{l}-1}
$$

Given the determination of operating profits, we can now turn to the dynamic aspect of the firm's decision making problem, which includes the investment and payout decisions. The firm can finance investment with internal funds, which consist of operating profits $\pi\left(k_{t}^{j}, z_{t}^{j} ; w_{t}\right)$ net of taxes $\tau_{c, t}\left(\pi\left(k_{t}^{j}, z_{t}^{j} ; w_{t}\right)-\delta k_{t}^{j}\right)$, where $\tau_{c, t}$ is a flat corporate income tax rate and $\delta \in[0,1]$ is the capital depreciation rate. Note that deductions from taxable income include a depreciation allowance $\delta k_{j t}$. Funds can be allocated to dividends $d_{t}^{j}$ or capital expenditures, the latter consisting of new additions to the capital stock $x_{j, t}$ and capital adjustment $\operatorname{costs} \phi\left(x_{t}^{j} / k_{t}^{j}\right)$ that are proportional to the existing capital stock. Thus, the firm's financing constraint is given by:

$$
d_{t}^{j}+x_{t}^{j}+\phi\left(x_{t}^{j} / k_{t}^{j}\right) k_{t}^{j}=\pi\left(k_{t}^{j}, z_{t}^{j} ; w_{t}\right)-\tau_{c, t}\left[\pi\left(k_{t}^{j}, z_{t}^{j} ; w_{t}\right)-\delta k_{t}^{j}\right]
$$

We assume that dividends cannot be negative:

$$
d_{j t} \geq 0
$$

The firm's capital stock evolves according to:

$$
k_{t+1}^{j}=x_{t}^{j}+(1-\delta) k_{t}^{j} .
$$

We assume that firm $j$ maximizes its value, $V_{t}^{j}$, which is equal to: ${ }^{6}$

$$
V_{t}^{j}=\left(1-\tau_{d, t}\right) d_{t}^{j}+P_{t}^{j}-\tau_{g, t}\left(P_{t}^{j}-P_{t-1}^{j}\right)=\left(1-\tau_{d, t}\right) d_{t}^{j}+\left(1-\tau_{g, t}\right) P_{t}^{j}+\tau_{g, t} P_{t-1}^{j} .
$$

Using (3), it is easy to see that the ex dividend firm price is related to the firm value as follows:

$$
P_{t}^{j}=E_{t}\left[m_{t, t+1}\left(\left(1-\tau_{d, t+1}\right) d_{t+1}^{j}+P_{t+1}^{j}-\tau_{g, t+1}\left(P_{t+1}^{j}-P_{t}^{j}\right)\right)\right]=E_{t}\left[m_{t, t+1} V_{t+1}^{j}\right],
$$

\footnotetext{
${ }^{6}$ This is the objective that all shareholders agree with, see Carceles-Poveda \& Coen-Pirani (2009).
} 
where $m_{t, t+1}$ is defined as in the previous section. In turn, this implies that the objective of the firm can be written as:

$$
V_{t}^{j}=\left(1-\tau_{d, t}\right) d_{t}^{j}+\left(1-\tau_{g, t}\right) E_{t}\left[m_{t, t+1} V_{t+1}^{j}\right]+\tau_{g, t} P_{t-1}^{j}
$$

This allows us to write the problem of the firm in recursive form. However, in addition to the natural state variables $\left(k_{t}^{j}\right.$ and $z_{t}^{j}$ ) of the model, the past price $P_{t-1}^{j}$ also becomes a state variable. Denote $P_{t-1}^{j}$ by $P_{-}$. Taking $\left\{w_{t}, r_{t}, m_{t, t+1}, \tau_{d, t}, \tau_{c, t}\right\}_{t=1}^{\infty}$ as given, the firm solves the following recursive problem:

$$
\begin{aligned}
W_{t}^{f}\left(z, k, P_{-}\right)= & \max _{x, k^{\prime}, d, P}\left(1-\tau_{t}^{d}\right) d+\tau_{t}^{g} P_{-}+\left(1-\tau_{t}^{g}\right) E_{t} m_{t, t+1} W_{t+1}^{f}\left(z^{\prime}, k^{\prime}, P\right) \text { s.t. } \\
d & =\pi\left(k, z ; w_{t}\right)-\tau_{c, t}\left[\pi\left(k, z ; w_{t}\right)-\delta k\right]-\phi(x / k) k-x \\
d & \geq 0 \\
k^{\prime} & =x+(1-\delta) k \\
P & =E_{t}\left[m_{t, t+1} W_{t+1}^{f}\left(z^{\prime}, k^{\prime}, P\right)\right] .
\end{aligned}
$$

where $W^{f}$ represents the value of the firm.

Let $\lambda$ be the multiplier on the non-negativity constraint on dividends, $q$ the multiplier on the capital accumulation constraint and $\gamma$ the multiplier on the price constraint. The optimality conditions with respect to labor, investment, capital and the price are:

$$
\begin{aligned}
w_{t} & =(1-\alpha)(k / l)^{\alpha} \\
q & =\left(1-\tau_{d, t}+\lambda\right)\left(1+\phi^{\prime}(x / k)\right) \\
q & =\left[1-\tau_{g, t}+\gamma\right] E_{t}\left[m_{t, t+1} \frac{\partial W_{t+1}^{f}\left(z^{\prime}, k^{\prime}, P\right)}{\partial k^{\prime}}\right] \\
\gamma & =\left[1-\tau_{g, t}+\gamma\right] E_{t}\left[m_{t, t+1} \frac{\partial W_{t+1}^{f}\left(z^{\prime}, k^{\prime}, P\right)}{\partial P}\right] .
\end{aligned}
$$


The envelope conditions with respect to $k$ and $P$ are:

$$
\begin{aligned}
\frac{\partial W_{t+1}^{f}\left(z, k, P_{-}\right)}{\partial k} & =\left(1-\tau_{d, t}+\lambda\right)\left[\pi_{k}\left(k, z ; w_{t}\right)-\tau_{c, t}\left(\pi_{k}\left(k, z ; w_{t}\right)-\delta\right)-\phi\left(\frac{x}{k}\right)+\phi^{\prime}\left(\frac{x}{k}\right) \frac{x}{k}\right] \\
& +q(1-\delta) \\
\frac{\partial W_{t+1}^{f}\left(z, k, P_{-}\right)}{\partial P_{-}} & =\tau_{g, t} .
\end{aligned}
$$

Combining the second envelope condition with (18), we have

$$
\gamma=\frac{\left[1-\tau_{g, t}\right] E_{t}\left[m_{t, t+1} \tau_{g, t+1}\right]}{1-E_{t}\left[m_{t, t+1} \tau_{g, t+1}\right]}
$$

With this equation, we can rewrite the firm's optimality condition with respect to capital in (17) as follows:

$q=\frac{\left(1-\tau_{g, t}\right) E_{t} m_{t, t+1}\left[\left(1-\tau_{d, t+1}+\lambda^{\prime}\right)\left[\left(1-\tau_{c, t+1}\right) \pi_{k}^{\prime}+\tau_{c, t+1} \delta-\phi\left(\frac{x^{\prime}}{k^{\prime}}\right)+\phi^{\prime}\left(\frac{x^{\prime}}{k^{\prime}}\right) \frac{x^{\prime}}{k^{\prime}}\right]+q^{\prime}(1-\delta)\right]}{1-E_{t} m_{t, t+1} \tau_{g, t+1}}$.

If we substitute for $q^{\prime}$ from (16), the equation above becomes:

$q=\frac{\left(1-\tau_{g, t}\right) E_{t} m_{t, t+1}\left[\left(1-\tau_{d, t+1}+\lambda^{\prime}\right)\left[\left(1-\tau_{c, t+1}\right) \pi_{k}^{\prime}+\tau_{c, t+1} \delta-\phi\left(\frac{x^{\prime}}{k^{\prime}}\right)+\phi^{\prime}\left(\frac{x^{\prime}}{k^{\prime}}\right) \frac{k^{\prime \prime}}{k^{\prime}}+1-\delta\right]\right]}{1-E_{t} m_{t, t+1} \tau_{g, t+1}}$.

The condition in eq. (15) pins down the wage rate given capital intensity $k / l$. The optimality condition with respect to investment in (16) determines the shadow price of installed capital, or Tobin's q. The condition in eq. (20) is the firm's Euler equation. The left-hand side denotes the marginal cost of one unit of investment today which is the shadow price of capital. The gain is shown on the right-hand side of the equation. This gain realizes in the following period which explains why we discount it. The marginal unit of installed capital increases tomorrow's after-tax profits. Furthermore, depending on the firm's optimal investment decision tomorrow, investment today may reduce or increase the adjustment costs paid tomorrow, which is captured by the term $\phi^{\prime}\left(\frac{x^{\prime}}{k^{\prime}}\right) \frac{k^{\prime \prime}}{k^{\prime}}$. If the firm plans to extend its capital stock tomorrow, then today's investment is beneficial as it reduces tomorrow's cost of adjusting the capital. The opposite is true if the firm plans to run down the capital stock. Since the adjustment cost $\phi$ is assumed to be paid per unit of already installed capital stock, investment today raises tomorrow's adjustment costs by $\phi\left(\frac{x^{\prime}}{k^{\prime}}\right)$. Finally, the firm can use the un-depreciated capital from the one unit of installed capital today, which explains the term $q^{\prime}(1-\delta)$. Note that firms can be in two regimes. If $\lambda=0$, the firm is in the 
dividend distribution regime and $d>0$. If $\lambda>0$, the firm is in liquidity constrained regime and $d=0$.

It is easy to see that none of the key optimality conditions (15), (16) and (20) depends on $P_{-}$. Hence, the optimal dividend/investment policy does not depend on the past price either, since at the beginning of the period it is predetermined and it affects the firm value only additively. Using this, we can rewrite the firm's problem recursively as a function of $(z, k)$ only. To do this, notice that the ex dividend price in (3) can be written as:

$$
P_{t}^{j}=\frac{E_{t}\left[m_{t, t+1}\left[\left(1-\tau_{d, t+1}\right) d_{t+1}^{j}+\left(1-\tau_{g, t+1}\right) P_{t+1}^{j}\right]\right]}{1-E_{t} m_{t, t+1} \tau_{g, t+1}} .
$$

If we now substitute this into the expression for the cum-dividend firm value in (13), taking into account that $P_{t}^{j}=E_{t}\left[m_{t, t+1} V_{t+1}^{j}\right]$ as we established in (12), we obtain:

$$
V_{t}^{j}-\tau_{g, t} P_{t-1}^{j}=\left(1-\tau_{d, t}\right) d_{t}^{j}+\left(1-\tau_{g, t}\right) \frac{E_{t}\left[m_{t, t+1}\left[V_{t+1}^{j}-\tau_{g, t+1} P_{t}^{j}\right]\right]}{1-E_{t} m_{t, t+1} \tau_{g, t+1}} .
$$

Letting $W_{t}(z, k)=V_{t}^{j}-\tau_{g, t} P_{t-1}^{j}$, the problem of the firm can then be written recursively as follows:

$$
\begin{aligned}
W_{t}(z, k)=\max _{x, k^{\prime}, d}\left(1-\tau_{d, t}\right) d+\frac{1-\tau_{g, t}}{1-E_{t} m_{t, t+1} \tau_{g, t+1}} E_{t}\left[m_{t, t+1} W_{t+1}\left(z^{\prime}, k^{\prime}\right)\right] \text { s.t. } \\
d=\pi\left(k, z ; w_{t}\right)-\tau_{c, t}\left[\pi\left(k, z ; w_{t}\right)-\delta k\right]-\phi\left(\frac{x}{k}\right) k-x \\
d \geq 0 \\
k^{\prime}=x+(1-\delta) k .
\end{aligned}
$$

This problem has the same optimality conditions as the problem above. In what follows, we let $\mu_{t}^{f}(z, k)$ be the current cumulative population density over individual firm shocks and capital holdings. Finally, the policy functions corresponding to this problem are denoted by $k_{t}^{\prime}(z, k), x_{t}(z, k), d_{t}(z, k)$, and $l_{t}(z, k)$ and the stock price is $P_{t}(z, k)$.

\subsection{Government}

In each period $t$, the government collects taxes, consisting of corporate profit taxes, dividend taxes, capital gains taxes and income taxes, with rates of $\tau_{c}, \tau_{d}, \tau_{g}$ and $\tau_{l}$ respectively. We assume that the government maintains a balanced budget every period by transferring these taxes back to the households as lump-sum transfers $Z_{t}$. The government budget constraint 
is given by:

$$
Z_{t}=\tau_{d, t} D_{t}+\tau_{i, t} w_{t} L_{t}+\tau_{g, t} C G_{t}+\tau_{c, t}\left(\Pi_{t}-\delta K_{t}\right),
$$

where $D_{t}, L_{t}, K_{t}$ and $\Pi_{t}$ are the aggregate dividends, labor supply, capital and profits and $C G_{t}$ are the aggregate capital gains.

\subsection{Market Clearing}

At every period $t$, the stock market, the labor market and the goods markets clear:

$$
\begin{gathered}
\theta_{t+1}^{j}=1 \text { for all } j \\
n_{t}=L_{t} \\
c_{t}+\int_{j}\left[x_{t}^{j}+\phi\left(\frac{x_{t}^{j}}{k_{t}^{j}}\right) k_{t}^{j}\right] d j=\int z_{t}^{j} f\left(k_{i}^{j}, l_{t}^{j}\right) d j \\
b_{t+1}=0
\end{gathered}
$$

\subsection{Recursive Competitive Equilibrium}

In this environment a recursive competitive equilibrium can be defined (somewhat informally) as follows. For a given sequence of taxes $\tau=\left\{\tau_{l, t}, \tau_{c, t}, \tau_{d, t}, \tau_{g, t}\right\}_{t=1}^{\infty}$, we have prices $\left\{r_{t}, w_{t}, q_{t}, P_{t}\right\}_{t=1}^{\infty}$, household decision rules $\left\{c_{t}, \theta_{t+1}^{j}, b_{t+1}\right\}_{t=1}^{\infty}$ for all $j$ and $t>1$, firm decision rules $\left\{k_{t+1}(z, k), l_{t}(z, k), x_{t}(z, k), d_{t}(z, k)\right\}_{t=1}^{\infty}$, firm distributions $\left\{\mu_{t}^{f}(z, k)\right\}_{t=1}^{\infty}$, the

distribution laws of motion $\left\{\varphi_{t}^{f}\right\}_{t=1}^{\infty}$, government transfers $T_{t}$ and stochastic discount factors $m_{t, t+1}$ for all $t$, such that:

- given taxes and prices, the households' decision rules solve their maximization problem;

- given taxes, prices and the stochastic discount factor, the firm's decision rules solve their maximization problem;

- the market clearing conditions in (23)-(25) and the government budget constraint in (22) are satisfied;

- the distributions laws of motions are consistent with the household and firm decisions;

- the firm's discount factor $m_{t, t+1}$ is determined by the stochastic intertemporal rate of substitution of the representative household

In the Appendix, we describe the algorithms to compute both the initial steady-state and the transitional dynamics between the steady-states. 
Table 1: Model Parameters

\begin{tabular}{cll}
\hline Parameter & Description & Value \\
\hline Parameters & common across all models: & \\
$\tau_{d}$ & Dividend tax & $25 \%$ \\
$\tau_{g}$ & Capital gains tax & $20 \%$ \\
$\tau_{c}$ & Corporate tax & $34 \%$ \\
$\tau_{l}$ & Labor tax & $25 \%$ \\
$\sigma$ & Risk aversion & 1.0 \\
$\beta$ & Discount factor & 0.971 \\
$\alpha_{k}$ & Capital share in production & 0.311 \\
$\psi$ & Adjustment costs & 0.89 \\
$\delta$ & Depreciation rate & 0.095 \\
$T^{\star}$ & Period when uncertainty realizes & 10 \\
$p$ & Probability that reform continues & 0.5 \\
Representative firm model: & \\
$\alpha_{l}$ & Labor share in production & 0.689 \\
Heterogeneous firm model: & 0.65 \\
$\alpha_{l}$ & Labor share in production & $(0.767,0.211)$ \\
\hline
\end{tabular}

\section{Calibration}

\subsection{Overview}

Our benchmark economy assumes that there is a continuum of heterogeneous firms and a representative household. We calibrate this benchmark economy and maintain the same set of parameters in the economy with no heterogeneity whenever this is possible. All the parameters are displayed in Table 1. The time period is assumed to be one year.

The coefficient of relative risk aversion in the instantaneous utility function of the households in eq. (1) is set to $\sigma=1$. The discount factor, $\beta=0.97$, is set to match an interest rate of $4 \%$.

Households supply a fixed amount of labor (normalized to 1) to the firm. For the production function (5) and firm productivity shocks $z$, we use the calibration from Gourio \& Miao (2010). They estimate the degree of decreasing returns to scale using Compustat Industrial Annual Data. The production function parameters $\alpha_{k}$ and $\alpha_{l}$ are obtained by choosing $\alpha_{l}=0.65$ to match the average labor income share in US data and $\alpha_{k}=0.311$ to capture the estimated degree of decreasing returns to scale. The process for firm level productivity shocks is estimated by fitting an $\mathrm{AR}(1)$ process to the residuals $z_{t}$ of their 
estimated regression

$$
\ln z_{t}=\rho \ln z_{t-1}+\varepsilon_{t}, \varepsilon_{t} \sim N\left(0, \sigma^{2}\right)
$$

The estimated values for $\rho$ and $\sigma$ are 0.767 and 0.211 respectively. This process is approximated using a 10-state Markov chain, obtained by applying the method of Tauchen \& Hussey (1991). Finally, the adjustment cost function is assumed to be

$$
\phi(x / k)=\frac{\psi}{2}\left(\frac{x}{k}\right)^{2}
$$

and the parameter $\psi$ is chosen to match the cross-sectional volatility of investment rates of 0.156 in Compustat data from 1988 to 2002, as reported in Gourio \& Miao (2010). ${ }^{7}$ The depreciation rate $\delta=0.095$ is set to match the aggregate investment-capital ratio of 0.095 in the National Income and Product Accounts.

We would like to point out that our model with only convex costs of adjustment is able to replicate many of the features of lumpy investment that are discussed in the literature due to the presence of volatile idiosyncratic productivity shocks. To see this, we have provided a comparison of key moments of the investment rate distribution in Table 2.

\section{Table 2: Moments of the Investment Rate Distribution}

\begin{tabular}{lcc}
\hline & Data & Model \\
\hline Inactive $(|x / k|<0.01)$ & 8.1 & 3.3 \\
Positive $(x / k \geq 0.01)$ & 81.5 & 85.2 \\
Negative $(x / k \leq-0.01)$ & 10.4 & 11.5 \\
Positive spikes $(x / k \geq 0.2)$ & 18.6 & 10.4 \\
Negative spikes $(x / k \leq-0.2)$ & 1.8 & 0.04 \\
\hline
\end{tabular}

Notes: All numbers are in percent.

The first column of the table shows the data moments discussed in Cooper \& Haltiwanger (2006). In particular, the table displays the fraction of firms that are inactive (investment rates less than 0.01 in absolute value), the fraction of firms with positive or negative investment rates (defined as investment rates exceeding 0.01 in absolute value) and the fraction of firms that experience positive or negative spikes in investment (defined as investment rates exceeding 0.2 in absolute value). As the second column of the table shows (Model), our model captures several aspects typically associated with lumpy investment quite well. Our benchmark economy has $3.3 \%$ of firms that are inactive compared to $8.1 \%$ of firms in the data. In addition, more than $10 \%$ of firms experience positive investment spikes and many

\footnotetext{
${ }^{7}$ Cooper \& Haltiwanger (2006) find this volatility to be 0.337 in the Longitudinal Research Database (LRD). We use the value from Compustat since that dataset focuses on publicly traded corporations which are the relevant entities for our corporate tax experiments.
} 
less $(0.04 \%)$ firms experience negative investment spikes. The corresponding numbers in the data are $18.6 \%$ and $1.8 \%$ respectively. Finally, we also obtain the asymmetry of positive investment being more common than negative investment (85.2\% versus $11.5 \%$ ) very similar to the asymmetry in the data. Keeping in mind that our calibration did not target any of these statistics, we consider this a very good fit.

The fact that idiosyncratic productivity shocks can take us a long way towards fitting these data properties without the need for non-convex costs should not be surprising. Khan \& Thomas (2008) have already made this point. To be specific, Section 7.2 of that paper is devoted entirely to that point and shows that, as in our framework, "...before the inclusion of capital adjustment [fixed] costs, there is already a nontrivial cross-sectional distribution of plant investment rates determined by the distribution of plant-specific productivity shocks. Notice that these volatile idiosyncratic productivity shocks on their own cause both positive and negative investment spikes..." Khan \& Thomas (2008) then go further and provide "...new insights about how nonconvex adjustment costs influence investment at the plant" specifically showing that "...nonconvex costs do not cause lumpy investments, but act to eliminate them". In sum, the combination of the estimated idiosyncratic shock process together with the calibrated convex adjustment costs can take us a long way towards matching these features of the investment rate distribution.

Regarding government variables, we set the corporate tax rate $\tau_{c}=0.34$, which is roughly consistent with the statutory rate at the top bracket (0.35). The tax rates on dividends, labor income, and capital gains depend on the individual's income tax bracket, and we set them by assuming the average income. This results in a personal income tax rate of $\tau_{l}=0.25$ with the same rate for dividend taxes of $\tau_{d}=0.25$. Finally, the capital gains tax is set to $\tau_{g}=0.2$, which is the top statutory rate in effect since the American Taxpayer Relief Act of 2012 for a vast majority of households. ${ }^{8}$

Finally, we assume that $T^{*}=10$, which implies that uncertainty is resolved after 9 periods, namely the reforms either become permanent or they are permanently revoked. This aims at taking into account that both the Bush and the Trump tax cuts had provisions that were suppose to expire, subject to uncertainty, after 9 periods of the initial tax reforms.

As discussed earlier, we also conduct experiments in a model with no heterogeneity at all. In this case, the firm shocks are shut down and we maintain the same parameters as in the benchmark economy except for $\alpha_{l}$, which is set to $\alpha_{l}=1-\alpha_{k}$.

${ }^{8}$ The values of $20 \%$ are consistent with the 2013 federal average marginal income taxes on qualified dividends and long term capital gains reported by Feenberg \& Coutts (1993). 


\section{Results}

In the quantitative section, we will study the impact of two different tax reforms with and without policy uncertainty. In the first (shareholder tax cuts), we reduce dividends and capital gains taxes from $\tau_{d, t}=0.25$ and $\tau_{g, t}=0.2$ to $\tau_{d, t}=\tau_{g, t}=0.15$. These were the statutory levels for the dividends and capital gains taxes before and after the Bush shareholder tax cuts, implemented as part of the Jobs and Growth Tax Relief Reconciliation Act of 2003 (JGTRRA). In the second one (corporate tax cuts), we reduce the corporate $\operatorname{tax}$ from $\tau_{c, t}=0.34$ to $\tau_{c, t}=0.21$. These were the statutory levels before and after the Trump tax corporate cuts, which were implemented as part of the Tax Cuts and Jobs Act of 2017. We have chosen these two tax reforms for several reasons. First, both tax reforms implement substantial tax cuts. Second, as stated earlier, both tax reforms have been surrounded by policy uncertainty.

\subsection{Shareholder Tax Cuts}

\subsubsection{Shareholder Tax Cuts without Heterogeneity}

This section analyzes the results of the shareholder tax cuts mentioned above with no firm heterogeneity. The results of this reform with and without policy uncertainty are displayed in figure 1. The figure displays the path for different variables starting at the period where the reform happens unexpectedly, $t=1$, as a percentage deviation from the original steady state. In particular, the figure displays the paths for capital, consumption, the stock price, dividends, investment and the pre tax wage rate. In all the figures, the vertical dashed line corresponds to period $T^{\star}=0$, which is when uncertainty is resolved.

The paths for the different variables are displayed for two different scenarios: a permanent reform (solid blue line), and a reform with policy uncertainty. With policy uncertainty, there is only one path for the variables up to period $T^{\star}$. However, from then on, the economy can follow two different paths, depending on whether the reform becomes permanent or withdrawn.

Consider first the effect of a permanent reduction in both shareholder taxes. As the solid line in figure 1 illustrates, the tax reform delivers what it is designed for: it leads to a higher long run aggregate capital and investment. Investment jumps at impact and then slowly converges to its new steady value, implying a gradual increase in capital. From the resource allocation point of view, increasing investment leads to a short run reduction of consumption, which then increases gradually towards a higher steady state value in the long run. The increase in investment is also reflected in the representative firm's dividend policy, 

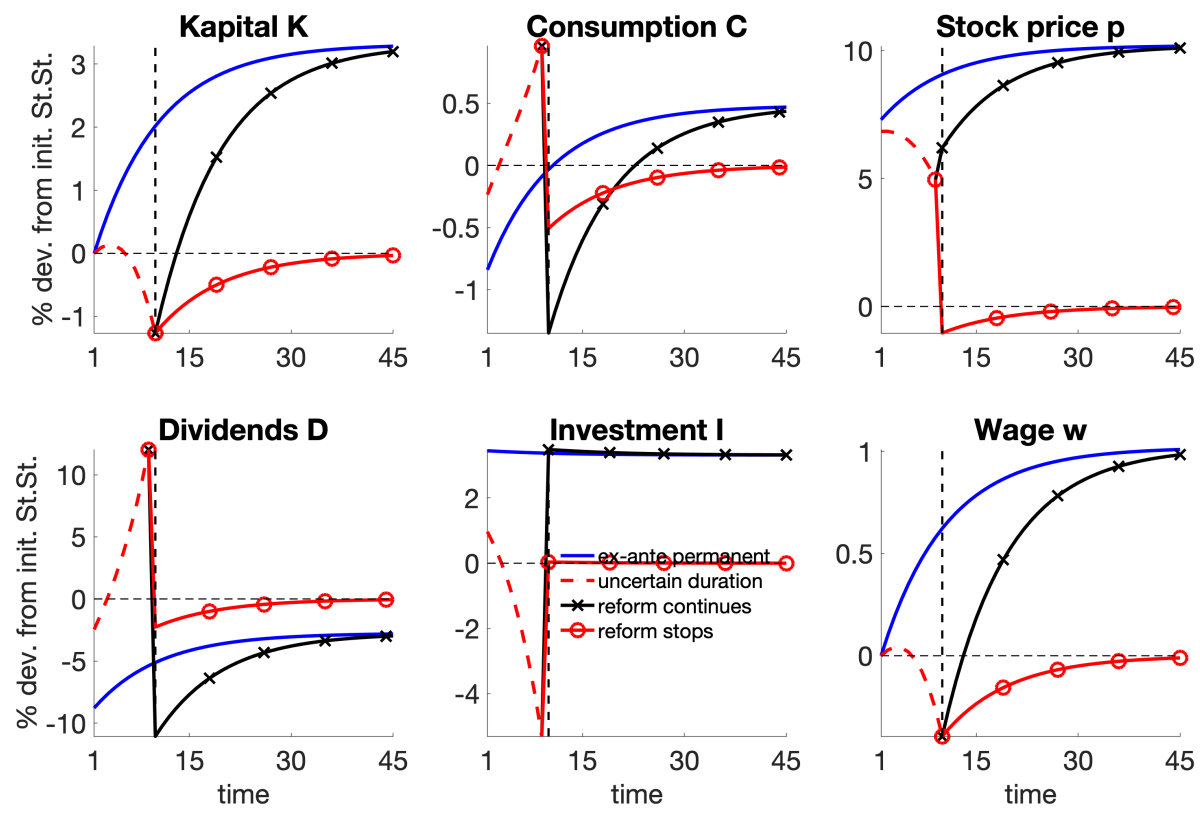

Figure 1: Dividend and Capital Gains Tax Cuts in the Model With No HetEROGENEITY

Notes: All numbers are in percent deviations from the pre-reform steady-state. The vertical dashed line corresponds to period $T^{\star}=10$ when uncertainty about reform duration realizes.

with a drop in (pre-tax) dividends at impact, with a gradual increase afterwards. As the third panel indicates, the higher investment is accompanied by an immediate jump in the value of the firm, followed by an increase towards a higher long run steady state. Note that, in the long run, the representative firm reaches its new steady state when the stock price is constant, and the value of the firm is given by the present discounted value of a constant flow of (after-tax) dividends. In spite of the fact that the (pre-tax) long run dividends remain lower than in the benchmark, the decrease in the dividend tax leads to higher net (after tax) dividends and hence a higher value of the firm both in the short and the long run.

When we look at the path of the same variables under policy uncertainty in Figure 1, we see that the paths after period $T^{\star}$ can converge either to the steady state associated with the permanent reform (solid-diamond line) or back to the old steady state (solid-circle line). However, we detect a very different pattern both qualitatively and quantitatively for the (comparable) first $T^{\star}-1=9$ periods. As reflected by the figures, all variables except the stock price move much less in magnitude. Moreover, in contrast to the permanent reform, there is a reduction in investment and capital (after a small initial increase). This is remarkable given that, with our parameterization, policy uncertainty is relatively small, as the reform will stay in place for a relatively long time (10 periods with certainty), after which there is still a 50 percent chance that it becomes permanent. In what follows, we 
dig deeper to try to understand where these large differences are coming from. In order to do that, it will be useful to study the effect of dividend tax cuts and capital gains tax cuts separately.

Figure 2 describes the effect of a pure dividend tax cut, with capital gains taxes remaining at the same level as in the status quo. Consider again the permanent reform. First, we note that a permanent dividend tax cut has no effects on the real allocations. Intuitively, this is due to the fact that both the marginal benefits and the marginal costs of increasing dividends today (or equivalently decreasing investment) are proportional to $1-\tau_{d, t}$. Hence, if we change dividend taxes permanently for all periods, this will not change the investment behavior.

Formally, this can be seen if we combine equations (16) and (20) to obtain the optimality condition with respect to investment:

$$
\begin{aligned}
\left(1-\tau_{d, t}+\lambda\right)\left(1+\phi^{\prime}\left(\frac{x}{k}\right)\right) & =\frac{\left(1-\tau_{g, t}\right) E_{t} m_{t, t+1}\left[\left(1-\tau_{d, t+1}+\lambda^{\prime}\right) R_{k}^{\prime}\right]}{1-E_{t} m_{t, t+1} \tau_{g, t+1}} \\
R_{k}^{\prime} & =\left(1-\tau_{c, t+1}\right) \pi_{k}^{\prime}+\tau_{c, t+1} \delta-\phi\left(\frac{x^{\prime}}{k^{\prime}}\right)+\phi^{\prime}\left(\frac{x^{\prime}}{k^{\prime}}\right) \frac{k^{\prime \prime}}{k^{\prime}}+1-\delta
\end{aligned}
$$
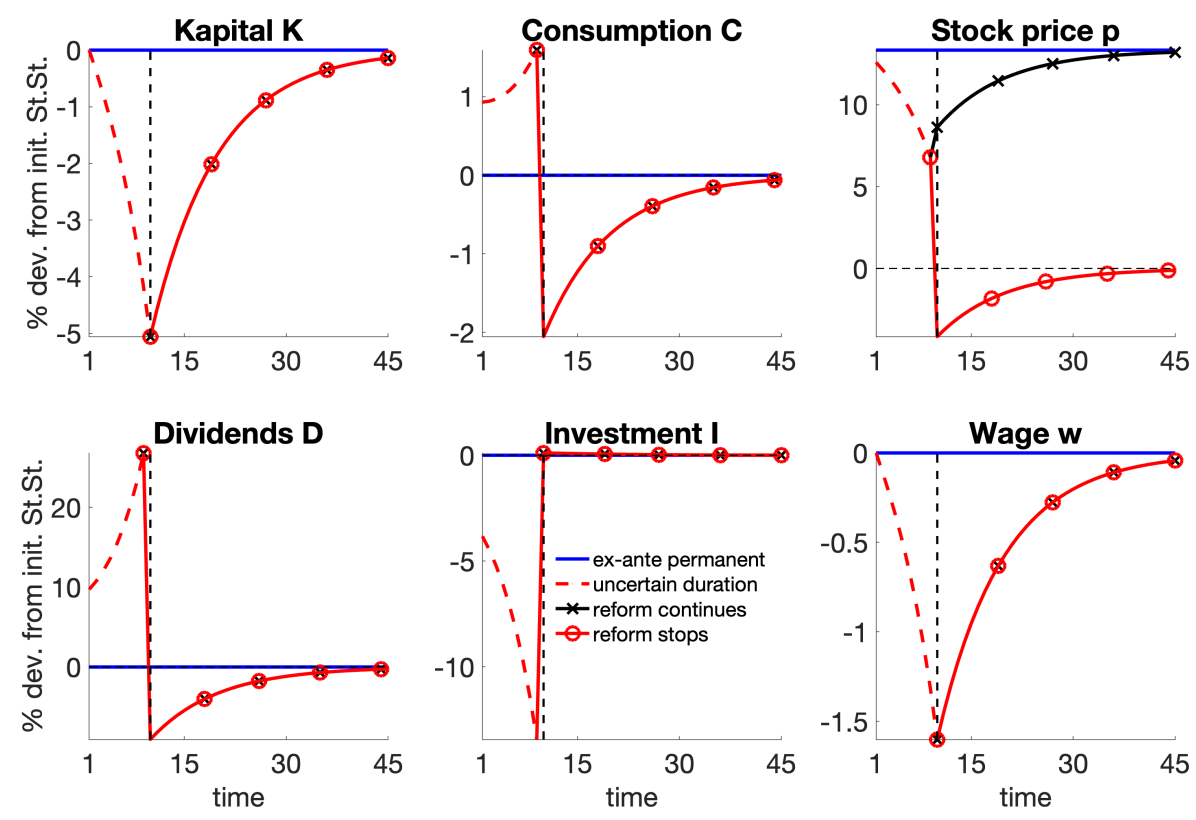

Figure 2: Dividend Tax Cuts in the Model With No Heterogeneity

Notes: All numbers are in percent deviations from the pre-reform steady-state. The vertical dashed line corresponds to period $T^{\star}=10$ when uncertainty about reform duration realizes.

In the rep/rep model, when the policy reform is permanent, there is no aggregate un- 
certainty and $\lambda_{t}=0$ for all time periods. Hence, constant dividend taxes will cancel out from this equation. Intuitively, when the shareholder considers an extra unit of an investment, this is equivalent at the margin to a comparison between paying less dividends in the current or the next period. As dividends are taxed at the same rate in both periods, the level of dividend taxes has no effect on investment. At the same time, since the net (after-tax) dividends jump at impact, the value of the firm increases immediately. Note that the government budget constraint is satisfied by a lump-sum tax equal to the value of the lost tax revenue, keeping consumption also unaffected.

In this reform, the paths under policy uncertainty are significantly different to the one in the permanent reform. In particular, investment drops substantially at impact and then continues to decrease until $T^{\star}-1$, while the path of dividends naturally mirrors this pattern in the opposite direction. We can understand this pattern by investigating the first order optimality condition (27) in period $T^{\star}-1$. In this period, we face an expected increase in dividend taxes as long as $p<1$. Hence, in this period, it is better, ceteris paribus, to pay out dividends rather than investing. Moreover, although dividend taxes remain constant between period 1 and $T^{\star}-1$, investment still changes due to two reasons. First, the representative household would like to smooth the increased consumption in period $T^{\star}-1$ to preceding periods. This will affect the paths through its effect on $m_{t, t+1}$, which appears in the discount factor of the firm. Second, we have convex adjustment costs and it is therefore optimal to also smooth out the decline in investment (capital). This effect will enter through the terms associated with $\phi(x / k)$ in $(27)$. In other words, in the absence of adjustment costs and with a constant firm discount factor, we would only see a change in investment at period $T^{\star}-1$. In sum, the presence of policy uncertainty generates tax arbitrage opportunities for the firm, who will find it optimal to front-load dividends and reduce investment in period $T^{\star}-1$, while the presence of convex adjustment costs and consumption smoothing motives expand this pattern for all preceding periods.

Figure 3 describes the effect of a pure capital gain tax cut, with dividend taxes remaining the same as in the status quo. Here, investment, and consequently consumption and capital, behave qualitatively the same way both under a permanent reform and under policy uncertainty before period $T^{\star}$. In order to see why investment increases, we can inspect optimality condition (27) again. Note that, in the steady state, we will have a higher investment and hence capital whenever the capital gains taxes are reduced because the firm discount factor $\beta \frac{1-\tau_{g}}{1-\beta \tau_{g}}$ is decreasing in $\tau_{g}$. As before, given convex adjustment costs and concave utility, these investment increases are distributed across all periods if the reform is permanent.

It seems surprising, however, that the short-term response of investment is larger under policy uncertainty. This is due to two effects. First, note that, in period $T^{\star}-1$, the 

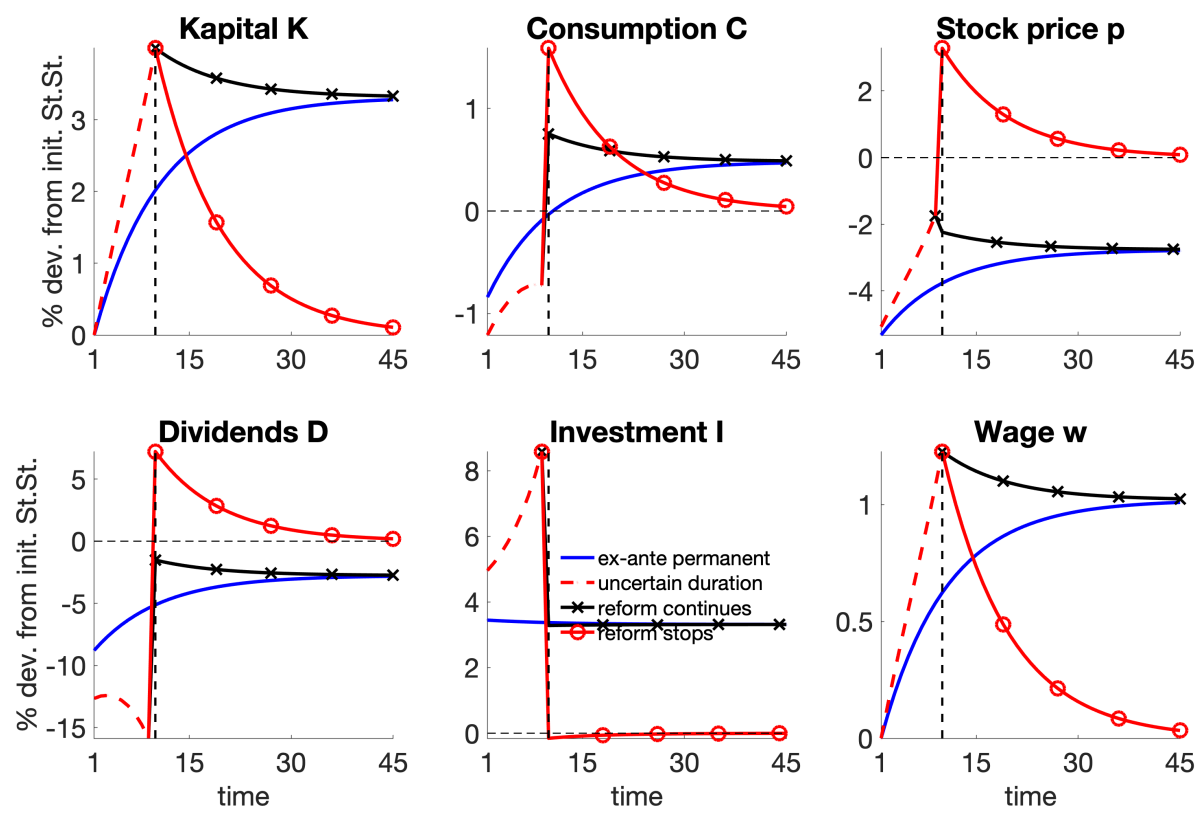

Figure 3: Capital Gains Tax Cuts in the Model With No Heterogeneity

Notes: All numbers are in percent deviations from the pre-reform steady-state. The vertical dashed line corresponds to period $T^{\star}=10$ when uncertainty about reform duration realizes.

representative household faces a stochastic tax rate, since the capital gains tax can go up as long as $p$ is different from zero. This implies that there is consumption risk that will lead to precautionary savings through the evolution of $m_{t, t+1}$ between periods 1 and $T^{\star}-1$. In turn, this implies that shareholders will consume less and invest (save) more than in the absence of policy uncertainty. Again, given convex adjustment costs and consumption smoothing motives, this will be translated into an investment increase in every period before $T^{\star}-1$. The second reason for a higher short-run investment under policy uncertainty is related to the path of the value of the firm. In our environment, if the value of the firm is increasing over time, the representative household pays capital gains taxes. In contrast, whenever the value of the firm is decreasing, the representative household is receiving tax rebates. Note that, between periods 1 and $T^{\star}-1$, the agent can take advantage of the lower tax rate on capital gains by letting the stock price $P$ grow and, if the tax reform is revoked in period $T^{\star}-1$, they can take advantage of the high tax rebates as the value of the firm is decreasing. In order to take advantage of this possible "arbitrage opportunity", the owner of the firm will invest more than she would do under a permanent reform in the presence of policy uncertainty. ${ }^{9}$ From the financial side, the increased investment is financed by reducing dividends in the short run and the value of the firm follows the path of the dividends.

\footnotetext{
${ }^{9}$ Note that if the reform is made permanent, the value of the firm is relatively constant so the level of capital gains taxes affecting income from owning the representative firm becomes lower.
} 
To sum it up, the policy uncertainty case delivers a negative change in investment in the case of a pure dividend tax cut, and a higher investment in the case of a pure capital gains tax reduction. As the Bush tax cuts were a combination of these two tax changes, the overall effect in Figure 1 is a modest and negative change in the case of policy uncertainty, implying that the dividend tax side of the reform dominates. In the case of a permanent reform, dividend taxes have no effect but capital gains tax reductions boost investment. Note that policy uncertainty brings about a tax arbitrage opportunity in both cases. In the case of dividend tax cuts, this opportunity is going against the intended effect of boosting investment, while in the case of capital gains taxes, it amplifies it.

\subsubsection{Shareholder Tax Cuts with Firm Heterogeneity}

In this section, we study how firm heterogeneity affects our results regarding the effect of policy uncertainty with the same shareholder tax reform we have studied above. In our model, idiosyncratic productivity shocks combined with financial and technological frictions lead to a rich distributions of firms in terms of productivity and capital size. Note that, for each level of productivity $z$, there is a desired level of capital, which we define as $k^{*}(z)$, which firms would like to attain. This level of capital is defined implicitly by $k^{\prime}\left(k^{*}(z), z\right)=k^{*}(z)$. Typically, however, firms cannot attain this desired level of capital immediately because of the financial constraints (they rely on internal resources only) and technological frictions (adjustment costs). Among the firms that have productivity $z$, we will going define growing

firms as firms with $k<k^{*}(z)$ and mature firms as firms with $k \geq k^{*}(z)$. Growing firms have a low level of capital relative to their productivity due to a recent positive productivity shock, while mature firms have already reached their desired productivity or are downsizing due to a recent negative productivity shock.

In the absence of capital adjustment costs, only mature firms $\left(k \geq k^{*}(z)\right)$ and growing firms that are very close to their target level (in the sense that they can achieve their target next period, $\left.k^{\prime}(k, z)=k^{*}(z)\right)$ pay dividends. Formally, in the absence of adjustment costs, the optimality condition with respect to capital in (27) becomes

$$
1-\tau_{d, t}+\lambda=\frac{\left(1-\tau_{g, t}\right) E_{t} m_{t, t+1}\left[\left(1-\tau_{d, t+1}+\lambda^{\prime}\right)\left(\left(1-\tau_{c, t+1}\right) \pi_{k}^{\prime}+\tau_{c, t+1} \delta+1-\delta\right)\right]}{1-E_{t} m_{t, t+1} \tau_{g, t+1}} .
$$

It is clear from this equation that firms with the same productivity who are paying dividends, $d>0$ and hence $\lambda=0$, will choose the same capital stock regardless of the current capital and they pay out as dividends all retained earnings in excess of the required investment. For all other growing firms that are far from their target, it is strictly preferred to invest all their retained earnings and not pay any dividends. 
In the presence of convex capital adjustment costs, however, the marginal cost of additional investment is increasing and this is reflected in a new term that appears on the left hand side of the capital optimality condition in (27). For growing firms, it increases the marginal cost of investment while for mature firms that are above their target level of capital it increases the marginal cost of downsizing, An important implication of this results is that, as opposed to simpler models of firm dynamics with financial frictions, financially constrained firms, in the sense that they are operating below their target level, may pay some dividends in our model.

Note also that not all mature firms pay dividends either. Some firms at $k^{*}(z)$ are betting on future productivity improvements and they only pay dividends under higher levels of productivity. This can be the optimal strategy if profit rates are relatively low, making the opportunity cost of not paying dividends small, and if the shocks are not very persistent, making productivity increases sufficiently likely. In our calibrated model, this turns out to be case for low productivity shocks. With these productivity shocks firms only pay dividends whenever they are considerably above the target level of capital.

In Table 3, we see the share of mature and growing firms that pay and don't pay dividends in the steady state. As reflected by the table, a large proportion of the mature firms, which happen to be the ones with a high share of capital, pay dividends and those who do not tend to be less productive than the average. At the same time, most of the growing firms do not pay pay any dividends.

Table 3: Firm-Heterogeneity: Summary Statistics in Pre-Reform SteadySTATE

\begin{tabular}{lcccccc}
\hline & \multirow{2}{*}{ Mass } & \multicolumn{5}{c}{ Share in Total: } \\
\cline { 3 - 7 } & & Capital & Output & Investment & Dividends & TFP \\
\hline Mature firms, $d^{j}>0$ & 31.14 & 46.64 & 26.26 & -5.75 & 83.61 & 79.39 \\
Mature firms, $d^{j}=0$ & 24.76 & 8.72 & 2.89 & 7.00 & 0 & 61.75 \\
Growing firms, $d^{j}>0$ & 3.82 & 11.58 & 19.91 & 21.75 & 13.69 & 111.13 \\
Growing firms, $d^{j}=0$ & 40.28 & 33.06 & 50.95 & 77.00 & 0 & 111.43 \\
\hline
\end{tabular}

Notes: The table shows some summary statistics in the pre-reform steady-state in the model with firm heterogeneity. All numbers are in percent.

Note that this is important, because it will determine how different firms will be affected by the reform and the policy uncertainty around it. In particular, high productivity mature firms close to their target level of capital are very similar to the representative firm in the previous subsection, as they pay dividends and they have low expected capital gains (or losses) before the reform. At the same time, firms that are significantly below their target 
level are very different, as they do not expect to pay dividends in the short run but have high expected capital gains. For this reason, we will show both the aggregate response of the economy to the tax change but also some disaggregated results for mature and growing firms.
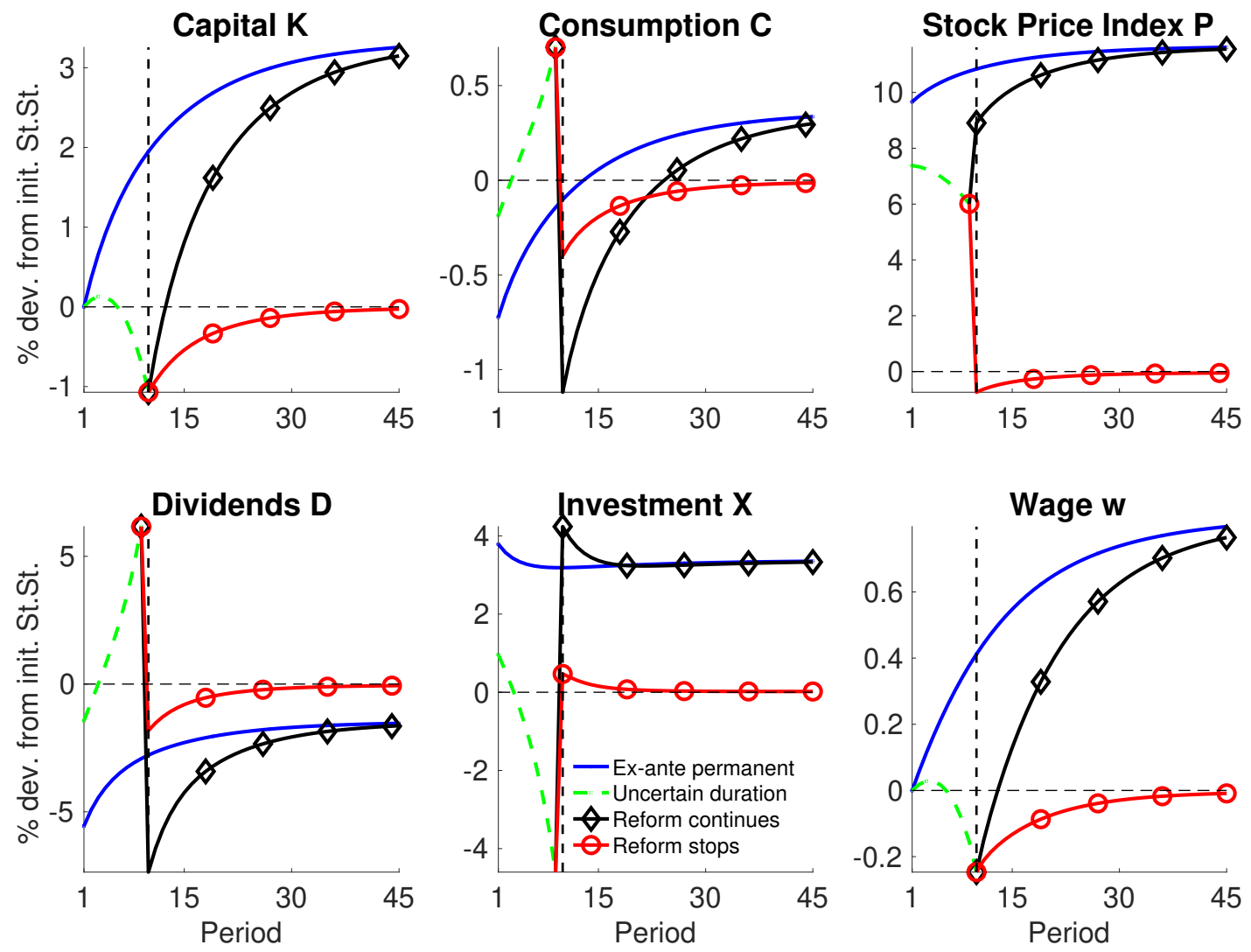

Figure 4: Shareholder Tax Cuts in the Model With Firm Heterogeneity Notes: All numbers are in percent deviations from the pre-reform steady-state. The vertical dashed line corresponds to period $T^{\star}=10$ when uncertainty about reform duration realizes.

Figure 4 shows the response of this economy to the exact same shareholder tax reform as before. The similarity to the case of a representative firm is remarkable, not only qualitatively but also quantitatively. In order to understand the results better, the next figures also provide some counterfactual simulations for the two different type of firms under three scenarios: no reform, permanent reform and policy uncertainty. To produce these results, we assume that the two different type of firms have the same level productivity but a different initial capital. ${ }^{10}$ A mature firm is initialised with $k_{1}=k^{*}(z)$ while the growing firm is initialised with a capital level considerably below the target level. We follow both firms with a (counterfactual) sequence of constant productivity. Note that, for the mature firms, this implies that all variables will remain constant without the reform.

\footnotetext{
${ }^{10}$ The shock is 29 percent higher than the firm's unconditional mean productivity.
} 
Figure 5 shows the response of a mature firm to the tax reform. The figure confirms that mature firms are the ones driving the aggregate results, as they behave practically the same way as the representative firm in the economy with firm. Figure 6 shows the results for a growing starting at $1 / 3$ of the target capital level. As before, the solid black curve shows the path of this firm in the absence of any reform while the pink dashed line shows the effect of a permanent reform. During the first periods of the transition, the growing firm uses all its retained earnings for investment and hence there is no effect on capital accumulation by either reform. As we discussed earlier the presence of convex adjustment costs implies that this firm will start paying dividends before reaching its target level of capital. For this firm, this happens before $T^{\star}$. Since the permanent reform increases the return on investment and investment is higher and dividends are lower than in the status quo. In contrast, policy uncertainty creates the same arbitrage opportunity as for mature firms and hence dampens investment both compared to the status quo and the permanent reform as in the other scenarios for these periods right before the reform. Note, however, that the effects on investment and dividends are much smaller for this firm compared to the mature firm because the arbitrage effect is quantitatively small and it only occurs for a few periods. In fact, in the appendix, we show that if the initial capital is significantly lower ( $1 / 10$ of the target capital), there is no effect of policy uncertainty at all as this firm will use all its retained earnings for investment for all periods $1 \leq t \leq T^{\star}$. Given these two figures, it is not surprising that the aggregate response to the tax reform closely resembles the response of a typical mature firm, as mature firms respond much more intensively to the reform.

A natural question is whether this asymmetric response has some consequences on the distribution of firms and on TFP. Here, we define TFP as:

$$
T F P_{t}=\frac{Y_{t}}{K_{t}^{\alpha_{k}} L_{t}^{\alpha_{l}}}
$$

where $K$ and $L$ are the aggregate capital and labor demand for all firms. Note that, under a permanent reform, mature firms increase their investment, compared to to the status quo with no reform in which they do pure replacement of depreciated capital, or reduce their disinvestment. In other words, at least temporarily, we will see more growing firms and less mature firms. Figure 7a show that, indeed, the share of firms that do not pay dividends immediately increases after the reform, with around 3 percent of firms who stop paying dividends and instead invest all their retained earnings. This implies that, after the permanent reform, mature firms become bigger in relative terms in the long run, while growing firms are to a large extent not affected. Table 3 shows that mature firms tend to be less productive. Hence, shareholder tax cuts allocate resources towards less productive 

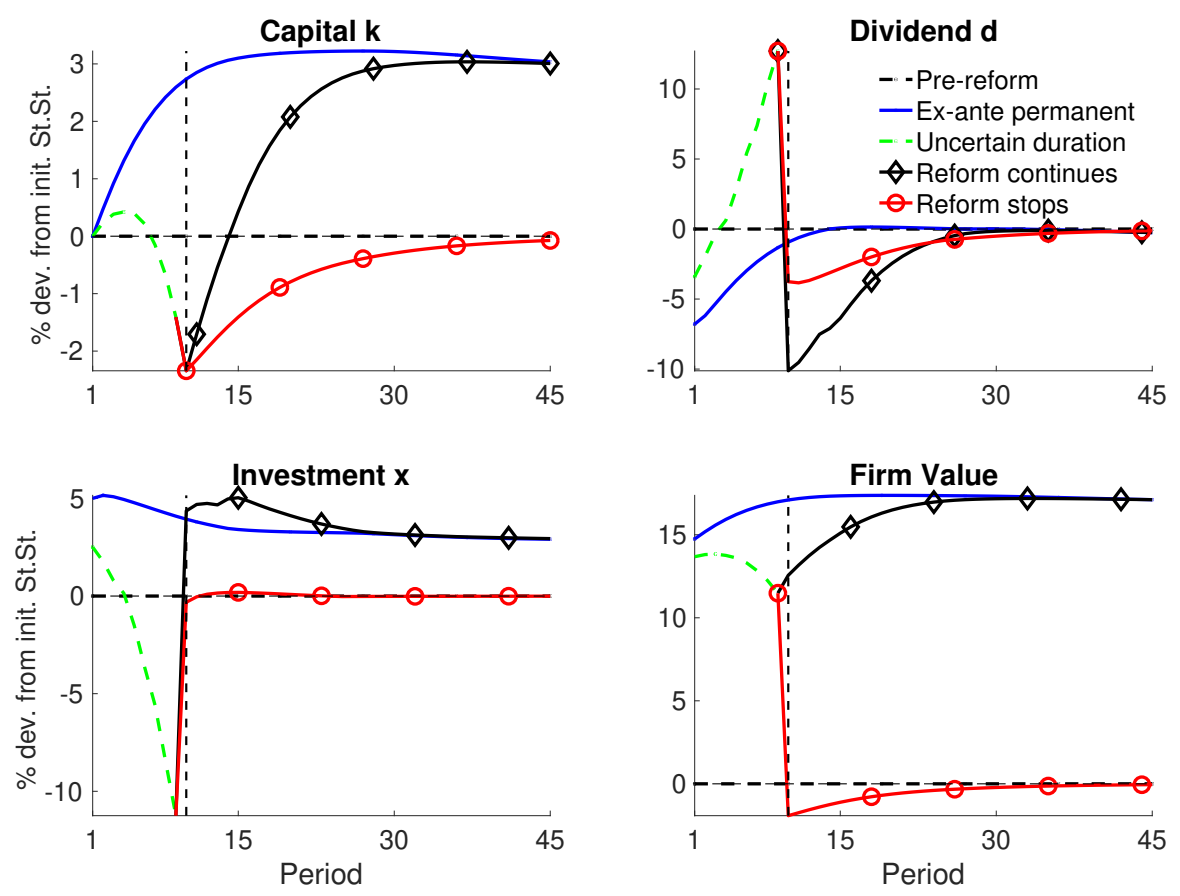

Figure 5: Shareholder Tax Cuts: Mature Firm

Notes: The figure shows a simulated time path of variables for a single firm. The firm starts at exactly the target capital level and faces the same stochastic productivity in each period. Pre-reform stands for a steady-state economy with constant taxes. All numbers are shown as percentage deviations from the firm's values in the pre-reform steady-state. The vertical dashed line corresponds to period $T^{\star}=10$ when uncertainty about reform duration realizes. 

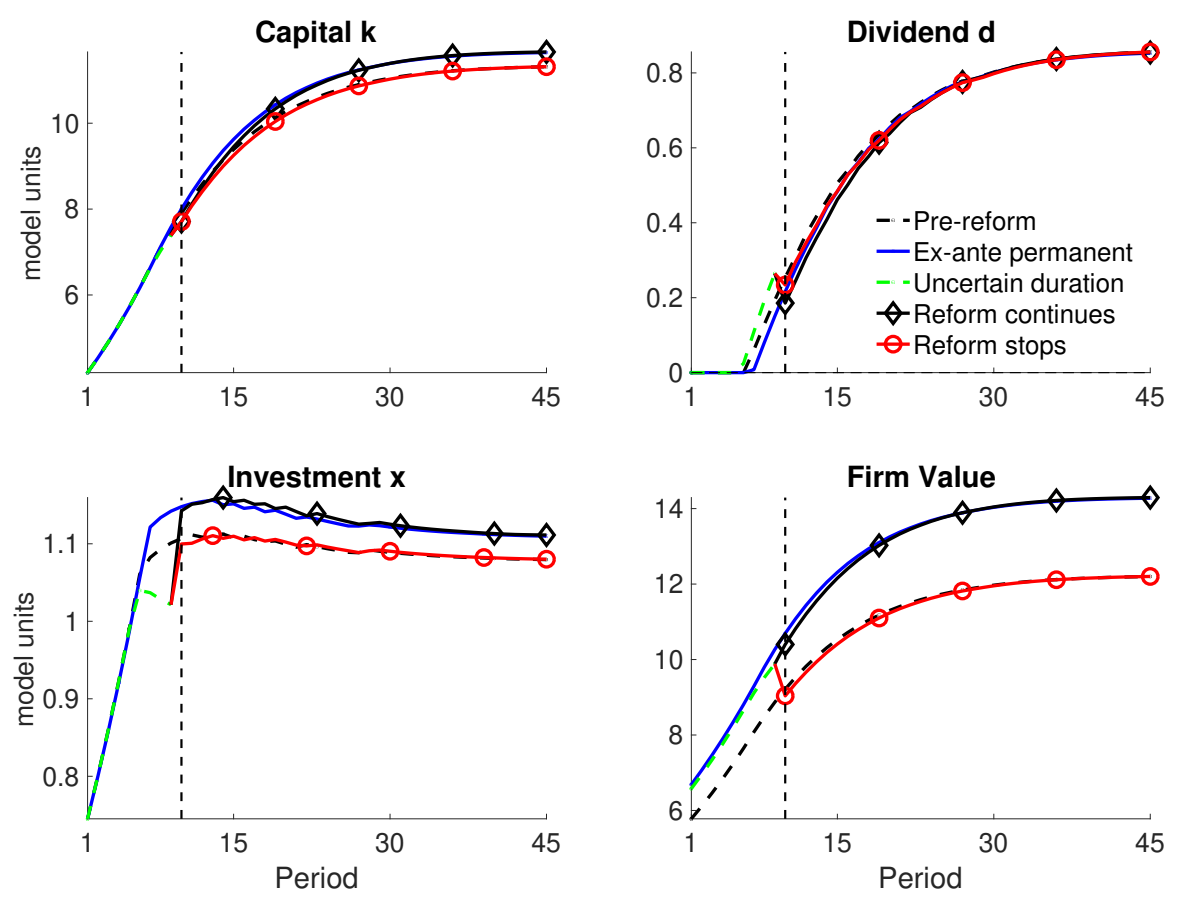

Figure 6: Shareholder Tax Cuts: Growing Firm

Notes: The figure shows a simulated time path of variables for a single firm. The firm starts at $1 / 3$ of the target capital level and faces the same stochastic productivity in each period. All numbers are shown in model units. Pre-reform stands for a steady-state economy with constant taxes. The vertical dashed line corresponds to period $T^{\star}=10$ when uncertainty about reform duration realizes. . 


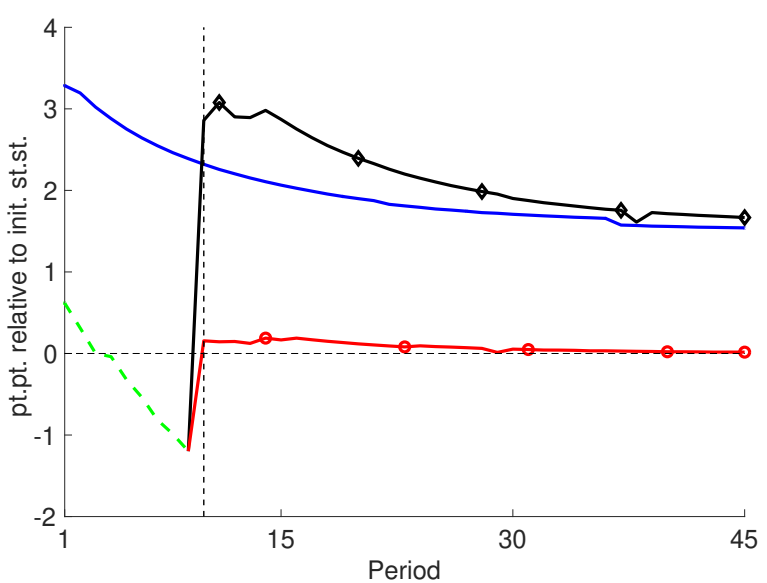

(a) Share of Dividend-Constrained Firms

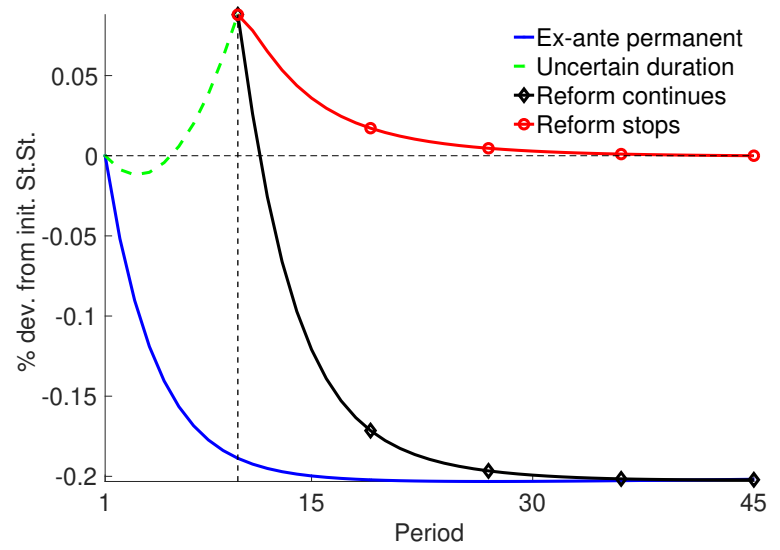

(b) TFP

Figure 7: Shareholder Tax Cuts in the Model With Firm Heterogeneity

Notes: Panel a) shows the cross-sectional share of dividend-constrained firms along the transition. The numbers are in percentage point deviations from the pre-reform steady-state. Panel b) plots the aggregate TFP as percent deviations from the pre-reform steady-state. In both panels, the vertical dashed line corresponds to period $T^{\star}=10$ when uncertainty about reform duration realizes.

firms, leading to a drop in TFP under the permanent reform. This is reflected in Figure $7 \mathrm{~b}$. Under policy uncertainty, the initial investment increase of the previously mature firms is largely mitigated, which implies a much smaller increase in the share of growing firms at impact. This leads to an initially much lower response of TFP. Further, before period $T^{\star}$, many firms start to pay dividends to take advantage of the tax arbitrage opportunities, leading to an increase in the ratio of dividend paying firms and reallocation towards more productive firms. This generates a modest increase in TFP before period $T^{\star}$. These changes in the allocation of capital have potential welfare consequences and we return to this question in the next subsection.

\subsubsection{Welfare}

Table 4 summarises the welfare effect of these shareholder tax reform for both the representative firm and heterogenous firm case. The welfare gains are measured as consumption equivalent compensations of the representative household taking into account the whole transition with and without policy uncertainty. The reforms bring about a modest welfare gain $0.18 \%$ for a permanent reform in the representative firm case. As we discussed before, the reduction of capital gains taxes reduces a distortion on investment, and positive welfare gains are expected. As we have also noticed before, policy uncertainty mutes the immediate impact of the reform on investment and introduces aggregate uncertainty in consumption. This reduces the welfare gains dramatically to $0.05 \%$. 
Table 4: Welfare Effects of Policy Reforms (CEV, \%)

\begin{tabular}{lcccccc}
\hline & \multicolumn{2}{c}{ No Heterogeneity } & & \multicolumn{2}{c}{ Firm Heterogeneity } \\
\cline { 2 - 3 } & $\begin{array}{c}\text { Ex-ante } \\
\text { Permanent }\end{array}$ & $\begin{array}{c}\text { Uncertain } \\
\text { Duration }\end{array}$ & & $\begin{array}{c}\text { Ex-ante } \\
\text { Permanent }\end{array}$ & $\begin{array}{c}\text { Uncertain } \\
\text { Duration }\end{array}$ \\
\hline Shareholder Tax & 0.18 & 0.05 & & 0.09 & 0.02 \\
Corporate Tax & 0.50 & 0.29 & & 0.82 & 0.50 \\
\hline
\end{tabular}

Notes: Welfare is measured as consumption equivalent variation at time $t=1$, taking the transitional dynamics into account. Welfare is shown in percent. A positive number indicates that the reform is welfare improving compared to the pre-reform steady-state.

Firm heterogeneity reduces further the welfare gains compared to the representative firm case, because the permanent reform causes misallocation of capital and a drop in TFP. Obviously, this effect is not present in the representative firm case. In the heterogenous firm case, policy uncertainty still has a smaller welfare effect ( 0.07 percentage point vs. 0.13 percentage points in the permanent reform). In terms of the muted response of investment and increased consumption volatility under policy uncertainty, the effects are the same as in the representative firm case. However, policy uncertainty practically eliminates the drop in TFP (capital misallocation) and hence welfare losses are mitigated.

Here, it is important to note that this exercise has maximised the amount of policy uncertainty by setting $p=0.5$. It is easy to see that, by reducing the probability of making the reform permanent below 0.5 , we can make this reform not desirable any more in terms of welfare. This is illustrated in Figure 8. As the figure illustrates, if policy uncertainty is such that the probability of withdrawing the reform is above 65 percent, $(p<0.35)$ then all the welfare gains disappear and the reform actually generates a welfare loss under policy uncertainty, with a welfare gain under a permanent reform.

This example shows that policy uncertainty can eliminate most of welfare gains of reforms that would clearly improve social welfare if there was a way to make sure that they will be permanent. Also note that by focusing on a representative household model we intentionally abstract from redistribution issues. In a heterogenous household environment, the welfare effect of such reforms depend on how the reform is financed even without policy uncertainty as the tax reform itself redistributes towards those who have more assets. See Abraham \& Carceles-Poveda (2006) and Anagnostopoulos et al. (2012) for more details for this case without policy uncertainty. 


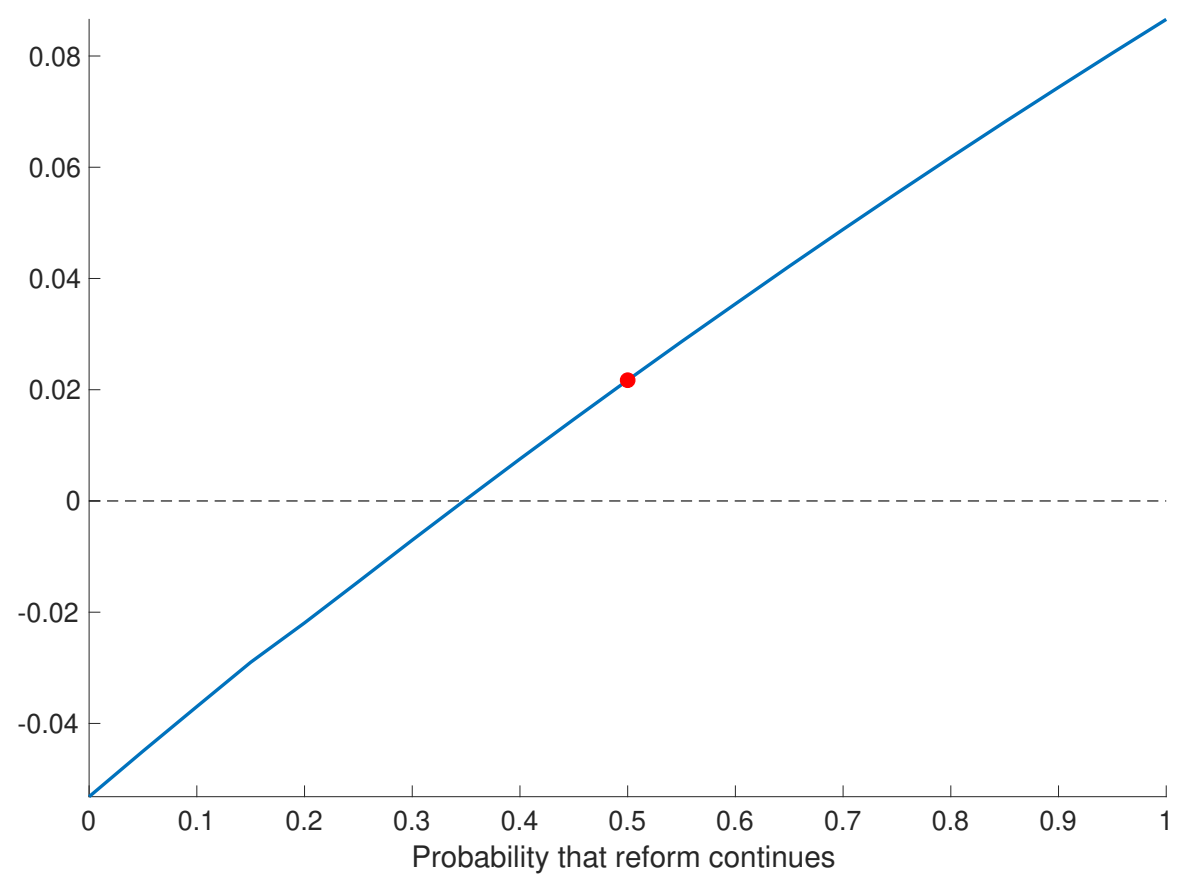

Figure 8: Shareholder Tax Reform: Welfare Effects as a Function of ProbABILITY $p(\mathrm{CEV}, \%)$

Notes: The figure analyzes the welfare effects of the shareholder tax reform as a function of probability $p$ that reform continues after $T^{\star}$. Welfare is measured as consumption equivalent variation at time $t=1$, taking the transitional dynamics into account. Welfare is shown in percent. A positive number indicates that the reform is welfare improving compared to the pre-reform steady-state. The red dot in the figure corresponds to the welfare in the benchmark model with $p=0.5$. 


\subsection{Corporate Tax Cuts}

In this section, we study the effects of the corporate tax reform discussed earlier . We will focus on the heterogenous firms case because, similarly to shareholder tax cuts, the aggregate dynamics are very close to the ones in the representative firm case. Figure 9 shows the path of aggregate variables under this reform, both for the permanent reform and under policy uncertainty. As reflected by the figure, this reform boosts investment and hence the capital stock in both cases. This should not be surprising, since a reduction of corporate taxes increases the return on investment. We can see this by observing the optimality condition on investment, (27), and by noticing that a reduction of $\tau_{c}$ increases the return to capital $R_{k}$ in the relevant case with $\pi_{k}^{\prime}>\delta$. In this sense, this reform is very similar to a pure capital gain tax reduction, which also increases the return on investment (see Figure 3).
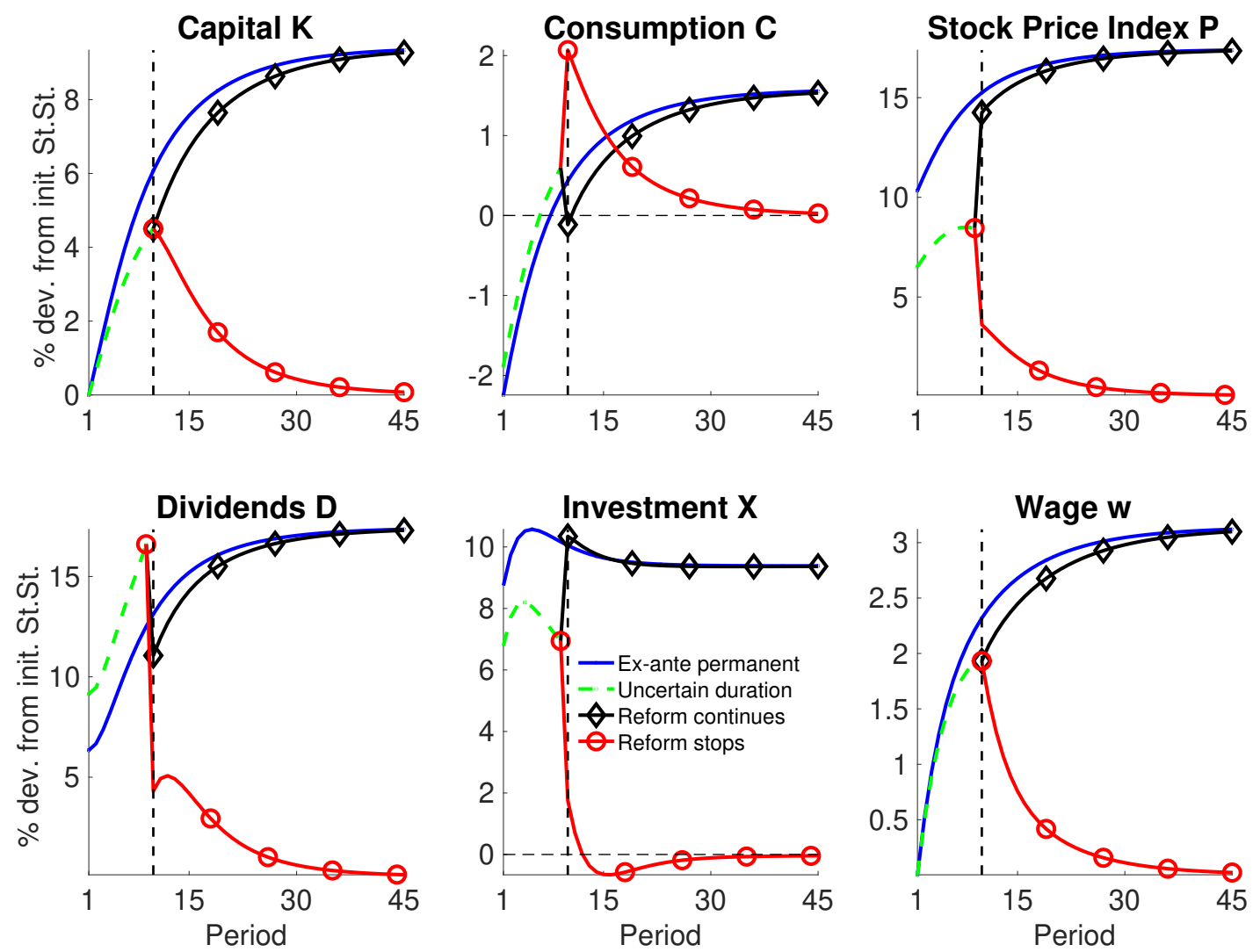

Figure 9: Corporate Tax Cuts in the Model With Firm Heterogeneity

Notes: All numbers are in percent deviations from the pre-reform steady-state. The vertical dashed line corresponds to period $T^{\star}=10$ when uncertainty about reform duration realizes.

At the same time, we see an important difference between this reform and the previous one when we consider policy uncertainty. In the case of a pure capital gains tax cut, policy uncertainty amplifies the response of investment, in the sense that investment increases more than under a permanent reform, while in the case of the corporate tax cut policy 
policy uncertainty mitigates the effect of the reform (up until period $T^{\star}$ ). As we explained in Section 4.1.1, if the capital gain tax cut is reversed, the firm value will start to decrease and hence firms will receive a subsidy (tax credits serve this purpose in the real world) through capital gains taxation. This effect will incentivize firms to over-invest and it is completely absent in the case of corporate tax cuts. The main effect in the latter case is the uncertainty in investment returns in period $T^{\star}-1$ and that reduces investment. Further, the presence of convex adjustment costs and the consumption smoothing motive for the representative household generates a gradual drop in investment in all the preceding periods as well.

This mechanism can be clearly seen on Figure 10 , where we show the effect of this reform on a mature firm ${ }^{11}$. In the figure, investment drops essentially to zero in period $T^{\star}-1$ due to return uncertainty. This drop rewinds back to make investment lower in all preceding periods. Nevertheless, the drop in investment is small in the early periods and hence the capital stock grows during the first stage of the transition.
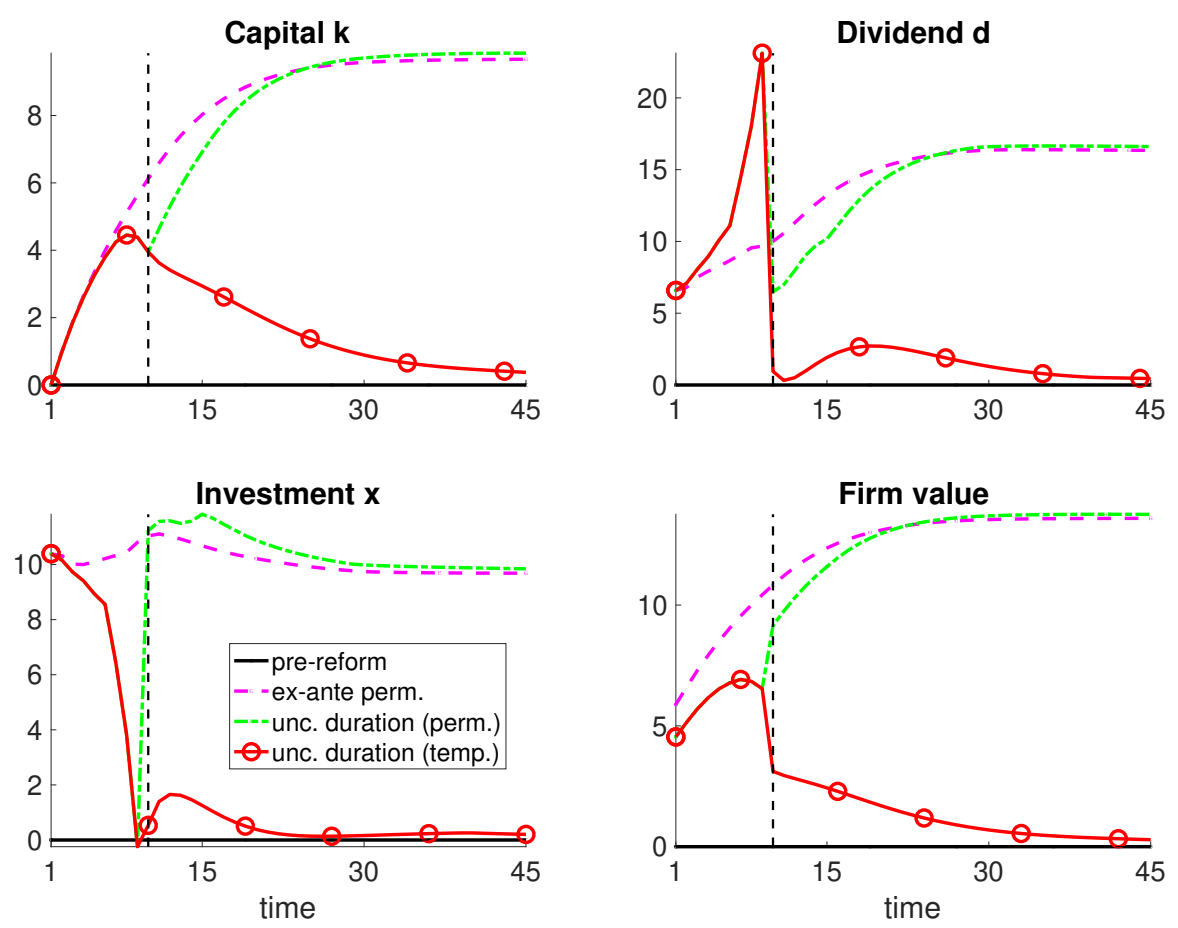

Figure 10: Corporate TAx Cuts: MAture Firm (percent deviations)

Notes: The vertical dashed line corresponds to period $T^{\star}=10$ when uncertainty about reform duration realizes.

We also see a similar pattern for growing firms on Figure 11. One important difference compared to the capital gain tax cuts is that this reform induces a rise in investment of growing firms from the beginning as well. The main reason is that corporate tax cuts

\footnotetext{
${ }^{11}$ Mature and growing firms are defined exactly in the same way as in the case of shareholder tax cuts.
} 

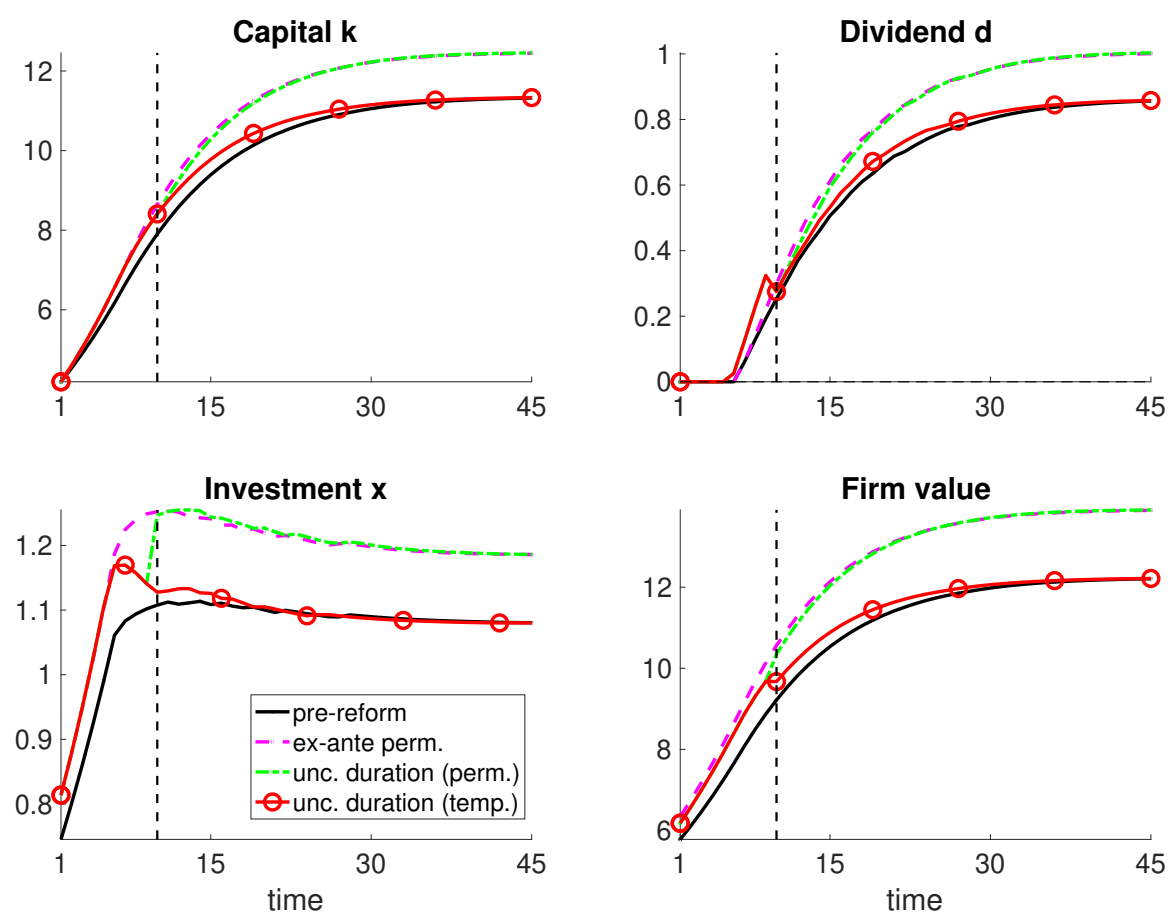

Figure 11: Corporate Tax Cuts: Growing Firm (absolute deviations)

Notes: The vertical dashed line corresponds to period $T^{\star}=10$ when uncertainty about reform duration realizes.

increase the retained earnings of these firms and as we discussed above, at an early stage of growth, they invest all their available resources. Capital gains tax cuts increase the income of the owners, but that does not relax the financing constraint of the firms. Nevertheless, these firms also decrease investment around period $T^{\star}-1$, as they start paying dividends and return uncertainty starts affecting them.

Another important difference compared to the shareholder tax cut case is in terms of the effect of the reform on TFP. We have seen in Figure 7b that permanent shareholder tax cuts lead to a decline in TFP. In contrast Figure 12 shows that permanent corporate tax cuts actually boost average TFP. The difference is coming from growing firms. Corporate tax cuts make growing firms invest proportionally more and this leads to a reallocation of capital in equilibrium towards more productive firms. The fact that policy uncertainty discourages mature firms from investment amplifies this reallocation and leads to an even higher boost in average TFP.

To sum it up, in the case of corporate tax cuts, policy uncertainty does not change qualitatively the path of key variables, but quantitatively mitigates the impact of the tax reform, with the exception of TFP when the effect is somewhat amplified. This is due to the fact that there are no tax arbitrage opportunities in the case of corporate tax cuts, whereas both components of the tax cut lead to arbitrage opportunities in the case of shareholder 


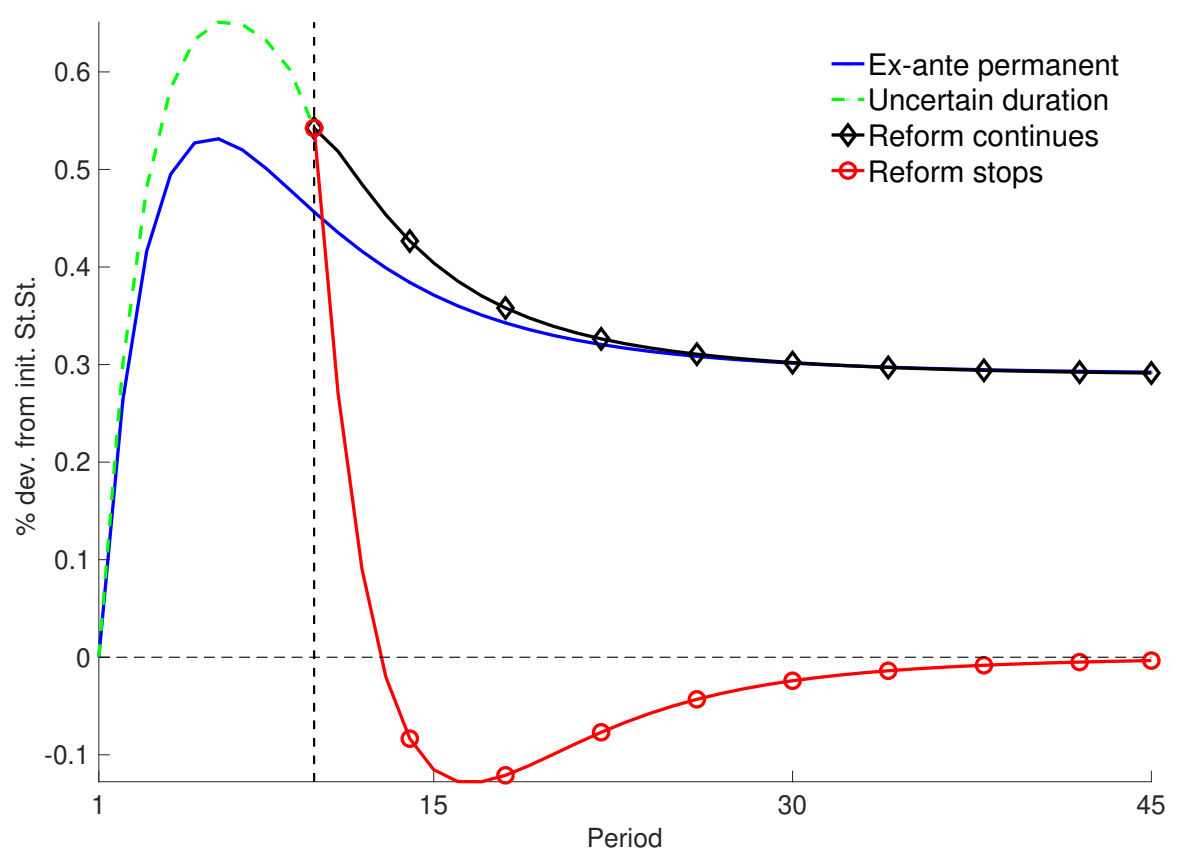

Figure 12: Corporate Tax Cuts in the Model With Firm Heterogeneity: TFP Notes: The vertical dashed line corresponds to period $T^{\star}=10$ when uncertainty about reform duration realizes.

tax cuts.

In terms of welfare, Table 4 shows that the corporate tax cut has a considerably larger welfare gain than the shareholder tax cut, both under a permanent reform and under policy uncertainty. Note that, when we compare the corporate tax reform to a pure capital gains tax cut, we obtain a higher welfare loss due to policy uncertainty, $42 \%$ versus $22 \%$, with a representative firm. This is due to the fact that policy uncertainty creates a new risk in both reforms that is detrimental to welfare. However, in the case of capital gains tax cuts, policy uncertainty amplifies the response of investment and hence the welfare loss is mitigated with respect to the corporate tax cut. In contrast, with heterogenous firms, corporate taxes generate additional positive reallocation (TFP) effect, leading to higher welfare gains.

\section{Conclusions}

This paper has analyzed the effects of policy uncertainty in the context of different capital tax reforms in a setting with potentially heterogeneous firms. Our results show that policy uncertainty has the potential to deliver very different results, both qualitatively and quantitatively, compared to a permanent reform. In particular, we study two different reforms that try to proxy important aspects of the Bush shareholder tax cuts and the Trump corporate tax cuts, and we show that policy uncertainty has bigger effects in the first reform, since 
the uncertainty in tax rates generates tax arbitrage opportunities that affect the agents' actions. We find that the paths for the main macroeconomic aggregates after the reform is implemented can be drastically different to the paths under a permanent reform for the periods before uncertainty is resolved. In particular, a dividend tax cut leads to a decrease in investment and an increase in dividend payments under policy uncertainty to take advantage of the lower dividend tax rates before uncertainty is resolved, while the opposite pattern is observed in the permanent reform. As for the capital gains tax cut, the reform under policy uncertainty leads to a higher investment under policy uncertainty than in the permanent re-

form, reflecting again tax arbitrage opportunities that allow agents to take advantage of the lower capital gains taxes by letting stock prices grow before uncertainty is resolved. Combining the two reforms, as in the Bush tax cuts, we obtain a muted response of investment, consistent with the data, which cannot be generated by the permanent reform. Finally, given that these tax arbitrage opportunities are not there, the response of investment is similar in the permanent and policy uncertainty reforms that lower corporate tax cuts, a case in which policy uncertainty does not affect the results qualitatively.

In this paper, we have modelled policy uncertainty as the probability that the reform might be either made permanent with some probability or be revoked irreversibly at a certain future date after it is implemented. Moreover, we have assumed that this probability is exogenous and equal to one half, which in a sense maximizes the effects of policy uncertainty. As we show in the paper, the size of the probability is crucial to determine the welfare gains of the shareholder tax cuts and we think it would be interesting to endogeneize it, something that we leave for further research. Our model provides a rich set of implications of how firms at a different stage of the life cycle would react to the different reforms. We would also like to study these implications empirically. We leave these issues for further research.

\section{References}

Abraham, A. \& Carceles-Poveda, E. (2006), 'Endogenous incomplete markets, enforcement constraints, and intermediation', Theoretical Economics 1(4), 439-459.

Anagnostopoulos, A., Atesagaoglu, O. E. \& Carceles-Poveda, E. (2018), Financing Corporate Tax Cuts with Shareholder Taxes, Department of Economics Working Papers 18-07, Stony Brook University, Department of Economics.

Anagnostopoulos, A., Carceles-Poveda, E. \& Lin, D. (2012), 'Dividend and capital gains taxation under incomplete markets', Journal of Monetary Economics 59(7), 599-611. 
Auerbach, A. J. (1979), 'Wealth Maximization and the Cost of Capital', The Quarterly Journal of Economics 93(3), 433-446.

Bradford, D. F. (1981), 'The incidence and allocation effects of a tax on corporate distributions', Journal of Public Economics 15(1), 1-22.

Caballero, R. J., Engel, E. M. R. A. \& Haltiwanger, J. C. (1995), 'Plant-Level Adjustment and Aggregate Investment Dynamics', Brookings Papers on Economic Activity 26(2), 154.

Caliendo, F. N., Gorry, A. \& Slavov, S. (2015), The cost of uncertainty about the timing of social security reform, Working Paper 21585, National Bureau of Economic Research.

Calvo, G. A. \& Drazen, A. (1997), Uncertain duration of reform: Dynamic implications, Working Paper 5925, National Bureau of Economic Research.

Carceles-Poveda, E. \& Coen-Pirani, D. (2009), 'Shareholders' unanimity with incomplete markets', International Economic Review 50(2), 577-606.

Conesa, J. C., Kitao, S. \& Krueger, D. (2009), 'Taxing capital? not a bad idea after all!', American Economic Review 99(1), 25-48.

Conesa, J. C. \& Krueger, D. (2006), 'On the optimal progressivity of the income tax code', Journal of Monetary Economics 53(7), 1425-1450.

Cooper, R. W. \& Haltiwanger, J. C. (2006), 'On the nature of capital adjustment costs', Review of Economic Studies 73, 611-633.

Dammon, R. M., Spatt, C. S. \& Zhang, H. H. (2001), 'Optimal Consumption and Investment with Capital Gains Taxes', Review of Financial Studies 14(3), 583-616.

Domeij, D. \& Heathcote, J. (2004), 'On the distributional effects of reducing capital taxes', International Economic Review 45(2), 523-554.

Feenberg, D. \& Coutts, E. (1993), 'An introduction to the taxsim model', Journal of Policy Analysis and Management 12(1), 189-194.

Feldstein, M. S. (1970), 'Corporate taxation and dividend behaviour', The Review of Economic Studies $\mathbf{3 7}(1), 57-72$.

Gavin, W. T., Kydland, F. E. \& Pakko, M. R. (2007), 'Monetary policy, taxes, and the business cycle', Journal of Monetary Economics 54(6), 1587-1611. 
Gourio, F. \& Miao, J. (2010), 'Firm heterogeneity and the long-run effects of dividend tax reform', American Economic Journal: Macroeconomics 2(1), 131-68.

Gourio, F. \& Miao, J. (2011), 'Transitional dynamics of dividend and capital gains tax cuts', Review of Economic Dynamics 14(2), 368 - 383.

Hall, R. E. \& Jorgenson, D. W. (1969), 'Tax policy and investment behavior: Reply and further results', The American Economic Review 59(3), 388-401.

Harberger, A. C. (1962), 'The incidence of the corporation income tax', Journal of Political Economy 70(3), 215-240.

Khan, A. \& Thomas, J. K. (2008), 'Idiosyncratic shocks and the role of nonconvexities in plant and aggregate investment dynamics', Econometrica 76(2), 395-436.

King, M. A. (1977), Public policy and the corporation, Vol. 3, Chapman and Hall; New York: Wiley.

Kitao, S. (2018), 'Policy uncertainty and cost of delaying reform: The case of aging Japan', Review of Economic Dynamics 27, 81-100.

Korinek, A. \& Stiglitz, J. E. (2009), 'Dividend taxation and intertemporal tax arbitrage', Journal of Public Economics 93(1), 142 - 159.

Poterba, J. M. \& Summers, L. H. (1983), 'Dividend taxes, corporate investment, and 'Q", Journal of Public Economics 22(2), 135-167.

Tauchen, G. \& Hussey, R. (1991), 'Quadrature-based methods for obtaining approximate solutions to nonlinear asset pricing models', Econometrica 59(2), 371-396.

Yagan, D. (2015), 'Capital tax reform and the real economy: The effects of the 2003 dividend tax cut', The American Economic Review 105(12), 3531-3563. 


\section{Computational Appendix}

Denote the initial steady-state quantities with a bar, e.g. $\bar{C}, \bar{k}$, etc. Denote the new steady state with a star, e.g. $C^{i \star}, k^{i \star}$. In all three types of models, assume that the initial steady state is associated with tax rates $\left(\bar{\tau}_{d}, \bar{\tau}_{g}, \bar{\tau}_{c}\right)$.

Assume that for $t \geq T$, the economy reaches a new steady state associated with tax rates $\left(\tau_{d}^{\star i}, \tau_{g}^{\star i}, \tau_{c}^{\star i}\right)$, where $i=s$ denotes the scenario, when the reform stops, and $i=c$ denotes the case when the reform continues after period $T^{\star}$. At time $t=1$, there is an unanticipated tax reform, so that taxes switch immediately (i.e. in the same period) to those in the final steady-state.

To simplify notation below, we index the relevant quantities by superscript $i$; however, by construction, the paths of these variables during $t=1, \ldots, T^{\star}-1$ (and for capital during $\left.t=1, \ldots, T^{\star}\right)$ are the same in both scenarios.

\section{Representative household / Representative firm model}

\subsection{Steady-state}

1. In a steady-state, the stochastic discount factor is given by $m=\beta$. The capital adjustment costs (per unit of capital) are given by $\phi=\frac{\psi}{2} \delta^{2}$. Combining the firm's first-order conditions (written in a steady-state):

$$
\begin{aligned}
q k & =\left(1-\tau_{g}\right) \frac{\beta}{1-\beta \tau_{g}}\left[\left(1-\tau_{d}\right) d+q k\right] \\
q & =\left(1-\tau_{d}\right)[1+\psi \delta]
\end{aligned}
$$

together with the definition of dividend:

$$
d=\left(1-\tau_{c}\right) \alpha k^{\alpha}+\tau_{c} \delta k-\delta k-\frac{\psi}{2} \delta^{2} k,
$$

compute the steady-state aggregate stock of capital in closed-form:

$$
k=\left[\frac{\left(1-\tau_{c}\right) \alpha\left(1-\tau_{g}\right)}{(1+\psi \delta) / \beta-1-\psi \delta+\left(1-\tau_{g}\right)\left(1-\tau_{c}+\frac{\psi}{2} \delta\right) \delta}\right]^{\frac{1}{1-\alpha}}
$$

- Given $k$ from the previous step, compute the wage rate, $w$, and the firm variables $\{x, y, \pi, d\}$. In particular, firm's investment is $x=\delta k$. 
- Compute the lump-sum transfer $T$ from the government budget constraint:

$$
T=\tau_{d} d+\tau_{l} w L+\tau_{c}(\pi-\delta k)
$$

where aggregate labor supply is fixed, i.e. $L=1$. Note that government revenues from capital gains taxation are zero in a steady-state.

- From the resource constraint, obtain aggregate consumption:

$$
C=y-x-\phi k
$$

- Compute the aggregate stock price, $P$, by integrating the household's Euler equation over all firms:

$$
P=\frac{\beta}{1-\beta}\left(1-\tau_{d}\right) d
$$

- Compute household's welfare as an infinite sum:

$$
W^{H}=\frac{1}{1-\beta} \times \frac{C^{1-\sigma}}{1-\sigma} .
$$

\subsection{Transitional dynamics}

1. Compute the initial steady state associated with tax rates $\left(\tau_{d, 1}, \tau_{g, 1}, \tau_{c, 1}\right)$. This is also the final steady-state in the case the reform is repealed. Compute the new steady state associated with tax rates $\left(\tau_{d, T}^{c}, \tau_{g, T}^{c}, \tau_{c, T}^{c}\right)$ in the case the reform is not repealed.

2. Guess the paths for the aggregate capital stock, $\left\{k_{t}^{i}\right\}_{t=2}^{T}$, and the path for the Lagrangian multipliers on the firm's non-negativity constraint for dividends, $\left\{\lambda_{t}^{i}\right\}_{t=1}^{T}$ for $i=\{c, s\}$. Note that $k_{1}^{i}=\bar{k}$ and $\lambda_{T}^{i}=0$. Also note that by construction, we must obtain identical paths for the variables during $t=1, \ldots, T^{\star}$ on both paths.

3. Given $\left\{k_{t}^{i}, \lambda_{t}^{i}\right\}_{t=1}^{T}$, compute wage rate, $\left\{w_{t}^{i}\right\}_{t=1}^{T}$, and firm variables $\left\{y_{t}^{i}, x_{t}^{i}, \phi_{t}^{i}, \pi_{t}^{i}, d_{t}^{i}\right\}_{t=1}^{T}$. If the implied guesses lead to a negative dividend, set $d_{t}^{i}=0$. Compute Tobin's q, $\left\{q_{t}^{i}\right\}_{t=1}^{T}$, using the firm's first-order condition:

$$
q_{t}^{i}=\left(1-\tau_{d, t}^{i}+\lambda_{t}^{i}\right)\left[1+\phi^{\prime}\left(x_{t}^{i} / k_{t}^{i}\right)\right]
$$


4. Compute aggregate consumption $\left\{C_{t}^{i}\right\}_{t=1}^{T}$ from the aggregate resource constraint:

$$
C_{t}^{i}=y_{t}^{i}-x_{t}^{i}-\phi\left(x_{t}^{i} / k_{t}^{i}\right) k_{t}^{i}
$$

5. Given $\left\{C_{t}^{i}\right\}_{t=1}^{T}$, compute a path of stochastic discount factors, $\left\{m_{t, t+1}^{i}\right\}_{t=1}^{T-1}$ :

$$
m_{t, t+1}^{i}=\beta\left(\frac{C_{t}^{i}}{C_{t+1}^{i}}\right)^{\sigma}
$$

6. Given $\left\{\lambda_{t}^{i}, d_{t}^{i}, q_{t}^{i}\right\}_{t=1}^{T}$ and $\left\{m_{t, t+1}^{i}\right\}_{t=1}^{T-1}$, proceed backwards from $T-2$ to 1 , use the firm's optimality condition to find a new path of capital, $\left\{\hat{k}_{t}^{i}\right\}_{t=1}^{T}$, as follows:

(a) Without policy uncertainty, use:

$$
\hat{k}_{t+1}^{i}=\frac{\left(1-\tau_{g, t}^{i}\right) \times m_{t, t+1}^{i} \times\left[\left(1-\tau_{d, t+1}^{i}+\lambda_{t+1}^{i}\right) d_{t+1}^{i}+q_{t+1}^{i} \hat{k}_{t+2}^{i}\right]}{q_{t}^{i} \times\left(1-\tau_{g, t+1}^{i} m_{t, t+1}^{i}\right)} .
$$

This optimality condition holds regardless of whether the firm is constrained or not at time $t$. Note that $\lambda_{t+1}^{i}$ (next period's Lagrangian multiplier), $q_{t+1}^{i}, k_{t+2}^{i}$, are given at time $t$, since we proceed backwards. Since we made a guess on $\lambda_{t}^{i}$, we also know $q_{t}^{i}$ from (29). Note that $\hat{k}_{T}^{c}=k^{\star}, \hat{k}_{T}^{s}=\bar{k}$ and $\lambda_{T}^{i}=0$.

(b) With policy uncertainty, use $(30)$ to find $\hat{k}_{t}^{i}$ in all periods except $T^{\star}-1$. At $T^{\star}-1$, use instead:

$$
\begin{aligned}
\hat{k}_{T^{\star}}^{i} & =\frac{\left(1-\tau_{g, T^{\star}-1}^{i}\right) \times z \times m_{T^{\star}-1, T^{\star}}^{c} \times\left[\left(1-\tau_{d, T^{\star}}^{c}+\lambda_{T^{\star}}^{c}\right) d_{T^{\star}}^{c}+q_{T^{\star}}^{c} \hat{k}_{T^{\star}+1}^{c}\right]}{(1-\Delta) q_{T^{\star}-1}^{i}} \\
& +\frac{\left(1-\tau_{g, T^{\star}-1}^{i}\right) \times(1-z) \times m_{T^{\star}-1, T^{\star}}^{s} \times\left[\left(1-\tau_{d, T^{\star}}^{s}+\lambda_{T^{\star}}^{s}\right) d_{T^{\star}}^{s}+q_{T^{\star}}^{s} \hat{k}_{T^{\star}+1}^{s}\right]}{(1-\Delta) q_{T^{\star}-1}^{i}}
\end{aligned}
$$

where

$$
\Delta \equiv\left(z \times \tau_{g, T^{\star}}^{c} \times m_{T^{\star}-1, T^{\star}}^{c}+(1-z) \times \tau_{g, T^{\star}}^{s} \times m_{T^{\star}-1, T^{\star}}^{s}\right) .
$$

7. Update the path of Lagrangian multipliers:

(a) If $d_{t}^{i}>0$, then the firm is unconstrained. Update the Lagrangian multiplier to $\hat{\lambda}_{t}^{i}=0$.

(b) If $d_{t}^{i}=0$, then the firm is constrained. 
i. Given $x_{t}^{i}$, use bisection to find $\hat{k}_{t}^{i}$ that satisfies $d_{t}^{i}=0$ :

$$
0=\left(1-\tau_{c, t}^{i}\right) \pi\left(\hat{k}_{t}^{i} ; w_{t}^{i}\right)+\tau_{c, t}^{i} \delta \hat{k}_{t}^{i}-\phi\left(x_{t}^{i} / \hat{k}_{t}^{i}\right) \hat{k}_{t}^{i}-x_{t}^{i}
$$

ii. Given $\left(q_{t}^{i}, \hat{k}_{t}^{i}, x_{t}^{i}\right)$, update the Lagrangian multiplier using (29):

$$
\hat{\lambda}_{t}^{i}=\frac{q_{t}^{i}}{1+\phi^{\prime}\left(x_{t}^{i} / \hat{k}_{t}^{i}\right)}-\left(1-\tau_{d, t}^{i}\right)
$$

8. Proceeding backwards from period $T-1$ to period 1 , compute household's welfare. In all periods, except $t=T^{\star}-1$, use:

$$
W_{t}^{H, i}=\frac{\left(C_{t}^{i}\right)^{1-\sigma}}{1-\sigma}+\beta W_{t+1}^{i}
$$

where $W_{T}^{H, i}=W^{H, i \star}$. At $t=T^{\star}-1$, use:

$$
W_{T^{\star}-1}^{H, i}=\frac{\left(C_{T^{\star}-1}^{i}\right)^{1-\sigma}}{1-\sigma}+\beta\left[z W_{T^{\star}}^{H, c}+(1-z) W_{T^{\star}}^{H, s}\right]
$$

9. Proceeding backwards from period $T-1$, compute aggregate stock price as follows:

$$
P_{t}^{i}=E_{t}\left[\frac{m_{t, t+1}^{i}}{1-E_{t}\left[m_{t, t+1}^{i} \tau_{g, t+1}^{i}\right]}\left[\left(1-\tau_{d, t+1}^{i}\right) d_{t+1}^{i}+\left(1-\tau_{g, t+1}^{i}\right) P_{t+1}^{i}\right]\right]
$$

where $P_{T}=P^{\star}$. The expectation operator only applies to period $t=T^{\star}-1$. To deal with policy uncertainty at $T^{\star}-1$, proceed similarly as in step 6 .

10. Compute transfers $\left\{T_{t}^{i}\right\}_{t=1}^{T}$ using the government budget constraint:

$$
T_{t}^{i}=\tau_{d, t}^{i} d_{t}^{i}+\tau_{l} w_{t}^{i} L+\tau_{c, t}^{i}\left(\pi_{t}^{i}-\delta k_{t}^{i}\right)+\tau_{g, t}^{i}\left(P_{t}^{i}-P_{t-1}^{i}\right)
$$

Note that $P_{0}^{i}=\bar{P}$.

11. Given $\left\{\hat{k}_{t}^{i}, \lambda_{t}^{i}\right\}_{t=1}^{T}$, update the guesses on $\left(k_{t}^{i}, \lambda_{t}^{i}\right)$. Return to step 3 . Repeat until convergence. 


\section{Heterogeneous firms / Representative household model}

\subsection{Steady-state}

1. Starting with a guess of wage $w$, solve the firm's dynamic programming problem by value function iteration:

- For a given state $(z, k)$, check first whether the firm is able to pay a non-negative dividend if it chooses $k^{\prime}=k_{1}$, where $k_{1}$ is the lowest point on the capital grid. If $d<0$ in this case, no solution for the firm's problem exists. Otherwise, proceed further.

- For a given state $(z, k)$, solve the firm's problem using value function iteration by looping over $k^{\prime}$ :

$$
W(z, k)=\max _{k^{\prime}}\left\{\left(1-\tau_{d}\right) d+\left(1-\tau_{g}\right) \frac{\beta}{1-\beta \cdot \tau_{g}} E_{z^{\prime} \mid z}\left[W\left(z^{\prime}, k^{\prime}\right)\right]\right\}
$$

where

$$
\begin{aligned}
d & =\pi(k, z ; w)-\tau_{c}[\pi(k, z ; w)-\delta k]-\phi(x / k) k-x \\
x & =k^{\prime}-(1-\delta) k \\
\phi(x / k) & =\psi \frac{(x / k)^{2}}{2} \\
\pi(k, z ; w) & =z k^{\alpha_{k}} l^{\alpha_{l}} \\
l & =\left[\frac{\alpha_{l} z k^{\alpha_{k}}}{w}\right]^{\frac{1}{1-\alpha_{l}}}
\end{aligned}
$$

- While looping over $k^{\prime}$, set $W(z, k)$ to a small negative number if the resulting value of dividend is negative.

2. After obtaining decision rules from the previous step, we solve for the stationary distribution of firms $\mu^{f}(k, z ; w)$.

3. After obtaining the stationary distribution of firms, we derive the aggregate labor demand. We then check whether the labor market clears, i.e. whether the aggregate labor demand is equal to 1 (recall that the aggregate labor supply is exogenous, i.e. $L=1$ ). If the equilibrium condition is not satisfied, we use the bisection method to update the wage rate and go back to Step 1. 
4. Compute transfers $T$ from the government budget constraint:

$$
T=\tau_{d} D+\tau_{l} w L+\tau_{c}(\Pi-\delta K)
$$

Note that government tax revenues from capital gains taxation are zero in a steadystate.

5. Compute aggregate stock index $P$ by integrating the household's first-order condition over all firms:

$$
P=\frac{\beta}{1-\beta}\left(1-\tau_{d}\right) D
$$

6. From the aggregate resource constraint, obtain aggregate consumption:

$$
C=Y-X-\Phi K
$$

7. Household's welfare is given by:

$$
W^{H}=\frac{1}{1-\beta} \times \frac{C^{1-\sigma}}{1-\sigma}
$$

\subsection{Transitional dynamics}

1. Compute the initial steady state associated with tax rates $\left(\bar{\tau}_{d}, \bar{\tau}_{g}, \bar{\tau}_{c}\right)$ and the new steady state associated with tax rates $\left(\tau_{d}^{\star i}, \tau_{g}^{\star i}, \tau_{c}^{\star i}\right)$. Denote the initial steady-state aggregate quantities with a bar, e.g. $\bar{C}, \bar{K}$, etc. Denote the new steady state with a star, e.g. $C^{\star}, K^{\star}$.

2. Guess a path for wages, $\left\{w_{t}^{i}\right\}_{t=1}^{T}$, and a path for stochastic discount factor, $\left\{m_{t, t+1}^{i}\right\}_{t=1}^{T-1}$.

3. Given $\left\{w_{t}\right\}_{t=1}^{T}$, solve firms problem using value function iteration, proceeding backwards from period $T-1$ to period 1 :

- For all periods, except $t=T^{\star}-1$, use:

$$
W_{t}^{i}(z, k)=\max _{k^{\prime}}\left\{\left(1-\tau_{d, t}^{i}\right) d^{i}+\left(1-\tau_{g, t}^{i}\right) \frac{m_{t, t+1}^{i}}{1-m_{t, t+1}^{i} \tau_{g, t+1}^{i}} W_{t+1}^{i}\left(z^{\prime}, k^{\prime}\right)\right\}
$$

where $W_{T}^{i}=W^{i \star}$. 
- At $t=T^{\star}-1$, use:

$$
\begin{aligned}
W_{T^{\star}-1}^{i}(z, k) & =\max _{k^{\prime}}\left(1-\tau_{d, T^{\star}-1}^{i}\right) d^{i} \\
& +\left[1-\tau_{g, T^{\star}-1}^{i}\right] \times \frac{z \times m_{T^{\star}-1, T^{\star}}^{c} \times W_{T^{\star}}^{c}\left(z^{\prime}, k^{\prime}\right)}{1-z \times m_{T^{\star}-1, T^{\star}}^{c} \times \tau_{g, T^{\star}}^{c}-(1-z) \times m_{T^{\star}-1, T^{\star}}^{s} \times \tau_{g, T^{\star}}^{s}} \\
& +\left[1-\tau_{g, T^{\star}-1}^{i}\right] \times \frac{(1-z) \times m_{T^{\star}-1, T^{\star}}^{s} \times W_{T^{\star}}^{s}\left(z^{\prime}, k^{\prime}\right)}{1-z \times m_{T^{\star}-1, T^{\star}}^{c} \times \tau_{g, T^{\star}}^{c}-(1-z) \times m_{T^{\star}-1, T^{\star}}^{s} \times \tau_{g, T^{\star}}^{s}}
\end{aligned}
$$

While looping over $k^{\prime}$, set $W_{t}^{i}(z, k)$ to a small negative number if the resulting value of dividend is negative. Note that

4. Compute aggregate consumption $\left\{C_{t}^{i}\right\}_{t=1}^{T}$ from the aggregate resource constraint:

$$
C_{t}^{i}=Y_{t}^{i}-X_{t}^{i}-\Phi_{t}^{i} K_{t}^{i}
$$

5. Given $\left\{C_{t}^{i}\right\}_{t=1}^{T}$ from the previous step, we compute a new path of stochastic discount factor, $\left\{\hat{m}_{t, t+1}^{i}\right\}_{t=1}^{T-1}$ :

$$
\hat{m}_{t, t+1}^{i}=\beta\left(\frac{C_{t}^{i}}{C_{t+1}^{i}}\right)^{\sigma}
$$

6. Proceeding backwards from period $T-1$, compute household's welfare as:

$$
W_{t}^{H, i}=\frac{\left(C_{t}^{i}\right)^{1-\sigma}}{1-\sigma}+\beta E_{t}\left[W_{t+1}^{H, i}\right]
$$

where $W_{T}^{i}=W^{\star}$. Again, the expectation operator applies only to period $t=T^{\star}-1$, where we have:

$$
W_{T^{\star}-1}^{H, i}=\frac{\left(C_{T^{\star}-1}^{i}\right)^{1-\sigma}}{1-\sigma}+\beta\left[z W_{T^{\star}}^{H, c}+(1-z) W_{T^{\star}}^{H, s}\right]
$$

7. Proceeding backwards from period $T-1$, compute aggregate stock price:

$$
P_{t}^{i}=E_{t}\left[\frac{m_{t, t+1}^{i}}{1-E_{t}\left[m_{t, t+1}^{i} \tau_{g, t+1}^{i}\right]}\left[\left(1-\tau_{d, t+1}^{i}\right) D_{t+1}^{i}+\left(1-\tau_{g, t+1}^{i}\right) P_{t+1}^{i}\right]\right]
$$

where $P_{T}^{i}=P^{\star}$. 
8. Compute transfers $\left\{T_{t}^{i}\right\}_{t=1}^{T}$ using the government budget constraint:

$$
T_{t}^{i}=\tau_{d, t}^{i} D_{t}^{i}+\tau_{l} w_{t}^{i} L+\tau_{c, t}^{i}\left(\Pi_{t}^{i}-\delta K_{t}^{i}\right)+\tau_{g, t}^{i}\left(P_{t}^{i}-P_{t-1}^{i}\right)
$$

Note that in the initial period $t=1$, the price is given by $P_{0}=\bar{P}$.

9. From the firm's problem, compute aggregate demand of labor, $\left\{L_{t}^{d, i}\right\}_{t=1}^{T}$. Update the wage $\left\{w_{t}^{i}\right\}_{t=1}^{T}$.

10. Update $m_{t, t+1}^{i}$ using $\hat{m}_{t, t+1}^{i}$ from step 5 . 